DP-MS-86-157

\title{
REPROCESSING OF NUCLEAR FUELS AT THE SAVANAAH RIVER PLANT
}

by

Leonard W. Gray

DP-MS $-86-157$

E. I. du Pont de Nemours and Company

Savannah River Laboratory

Aiken, South Carolina 29808

A paper invited for presentation before

the South Carolina Junior Academy of Science

University of South Carolina at Aiken

October 4, 1986.

This paper was prepared in connection with work done under Contract No. DE-AC09-76SR00001 with the U.S. Department of Energy. By acceptance of this paper, the publisher and/or recipient acknowledges the U.S. Government's right to retain a nonexclusive, royalty-free license in and to any copyright covering this paper, along with the right to reproduce and to authorize others to reproduce all or part of the copyrighted paper. 


\section{DISCLAIMER}

This report was prepared as an account of work sponsored by an agency of the United States Government. Neither the United States Government nor any agency Thereof, nor any of their employees, makes any warranty, express or implied, or assumes any legal liability or responsibility for the accuracy, completeness, or usefulness of any information, apparatus, product, or process disclosed, or represents that its use would not infringe privately owned rights. Reference herein to any specific commercial product, process, or service by trade name, trademark, manufacturer, or otherwise does not necessarily constitute or imply its endorsement, recommendation, or favoring by the United States Government or any agency thereof. The views and opinions of authors expressed herein do not necessarily state or reflect those of the United States Government or any agency thereof. 


\section{DISCLAIMER}

Portions of this document may be illegible in electronic image products. Images are produced from the best available original document. 
DP-MS-86-157

\section{REPROCESSING OF NUCLEAR FUELS AT THE SAVANNAH RIVER PLANT}

by

Leonard W. Gray

E. I. du Pont de Nemours and Company

Savannah River Laboratory

Aiken, South Carolina 29808

\section{ABSTRACT}

For more than 30 years, the Savannah River Plant (SRP) has been a major supplier of nuclear materials such as plutonium-239 and tritium-3 for nuclear and thermonuclear weapons, plut onium-238 for space exploration, and isotopes of americium, curium, and californium for use in the nuclear research community. SRP is a complete nuclear park, providing most of the processes in the nuclear fuel cycle. Rey processes involve fabrication and cladding of the nuclear fuel, target, and control assemblies; rework of heavy water for use as reactor moderator; reactor loading, operation, and unloading; chemical recovery of the reactor transmutation products and spent fuels; and management of the gaseous, liquid, and solid nuclear and chemical wastes; plus a host of support operations. The site's history and the key processes from fabrication of reactor fuels and targets to finishing of virgin plutonium for use in the nuclear weapons complex are reviewed. Emphasis has been given to the chemistry of the recovery and purification of weapons grade plutonium from irradiated reactor targets . 


\section{INTRODUCTION}

The Savannah River Plant (SRP) is one of the key installations in the U. S. Department of Energy's nationwide program of nuclear production and research. Today the site (Figure 1) comprises 192,000 acres, or 300 square miles, in Aiken, Barnwell, and Allendale Counties, South Carolina. Its land area is about equal to that of the City of New York.

SRP (Figure 2) has operated for more than 30 years as essentially the only U. S. supplier of tritium (hydrogen-3), is currently the only source of plutomium-238 for satellite power sources, and is the major supplier of virgin plutonium-239 for the nuclear weapons complex. Many other radionuclides can be made efficiently in Savannah River reactors. The product list over the years has included uranium-233, medical grade plutonium-238, americium-243, curium-244, polonium-210, cobalt-60, specific californium-252, and a host of minor products.

SRP is a complete nuclear park (Figure 3), including nuclear fuel fabrication, irradiation, and reprocessing. Key processes involve

- Fabrication and cladding of the nuclear fuel, target, and control assemblies

- Rework of heavy water, $D_{2} O$, the reactor coolant and moderator

- Reactor loading, operation, and unloading

- Chemical recovery of the reactor products and spent fuels 


\section{REPROCESSING OF NUCLEAR PUELS AT THE SAVANHAH RIVER PLANT}

by

Leonard W. Gray

E. I. du Pont de Nemours and Company

Savannah River Laboratory

Aiken, South Carolina 29808

A paper invited for presentation before

the South Carolina Junior Academy of Science

University of South Carolina at Aiken

October 4, 1986.

\section{DISCLAIMER}

This report was prepared as an account of work sponsored by an agency of the United States Government. Neither the United States Government nor any agency thereof, nor any of their employees, makes any warranty, express or implied, or assumes any legal liability or responsibility for the accuracy, completeness, or usefulness of any information, apparatus, product, or process disclosed, or represents that its use would not infringe privately owned rights. Reference herein to any specific commercial product, process, or service by trade name, trademark, manufacturer, or otherwise does not necessarily constitute or imply its endorsement, recommendation, of favoring by the United States Govermment or any agency thereof. The views and opinions of authors expressed herein do not necessarily state or reflect those of the United States Government or any agency thereof.

This paper was prepared in connection with work done under Contract No. DE-AC09-76SR00001 with the U.S. Department of Energy. By acceptance of this paper, the publisher and/or recipient acknowledges the U.S. Government's right to retain a nonexclusive, royalty-free license in and to any copyright covering this paper, along with the right to reproduce and to authorize others to reproduce all or part of the copyrighted paper. 


\section{REPROCESSING OF NUCLEAR FUELS AT THE SAVANNAH RIVER PLANT}

by

Leonard W. Gray

E. I. du Pont de Nemours and Company

Savannah River Laboratory

Aiken, South Carolina 29808

\section{ABSTRACT}

For more than 30 years, the Savannah River Plant (SRP) has been a major supplier of nuclear materials such as plutonium-239 and tritium-3 for nuclear and thermonuclear weapons, plutonium-238 for space exploration, and isotopes of americium, curium, and californium for use in the nuclear research community. SRP is a complete nuclear park, providing most of the processes in the nuclear fuel cycle. Key processes involve fabrication and cladding of the nuclear fuel, target, and control assemblies; rework of heavy water for use as reactor moderator; reactor loading, operation, and unloading; chemical recovery of the reactor transmutation products and spent fuels; and management of the gaseous, liquid, and solid nuclear and chemical wastes; plus a host of support operations. The site's history and the key processes from fabrication of reactor fuels and targets to finishing of virgin plutonium for use in the nuclear weapons complex are reviewed. Emphasis has been given to the chemistry of the recovery and purification of weapons grade plutonium from irradiated reactor targets.

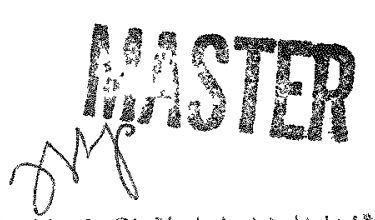




\section{INTRODOCTION}

The Savannah River Plant (SRP) is one of the key installations in the U. S. Department of Energy's nationwide program of nuclear production and research. Today the site (Figure 1) comprises 192,000 acres, or 300 square miles, in Aiken, Barnwell, and Allendale Counties, South Carolina. Its land area is about equal to that of the City of New York.

SRP (Figure 2) has operated for more than 30 years as essentially the only U. S. supplier of tritium (hydrogen-3), is currently the only source of plutomium-238 for satellite power sources, and is the major supplier of virgin plutonium-239 for the nuclear weapons complex. Many other radionuclides can be made efficiently in Savannah River reactors. The product list over the years has included uranium-233, medical grade plutonium-238, americium-243, curium-244, polonium-210, cobalt-60, specific californium-252, and a host of minor products.

SRP is a complete nuclear park (Figure 3 ), including nuclear fuel fabrication, irradiation, and reprocessing. Key processes involve

- Fabrication and cladding of the nuclear fuel, target, and control assemblies

- Rework of heavy water, $\mathrm{D}_{2} \mathrm{O}$, the reactor coolant and moderator

- Reactor loading, operation, and unloading

- Chemical recovery of the reactor products and spent fuels 


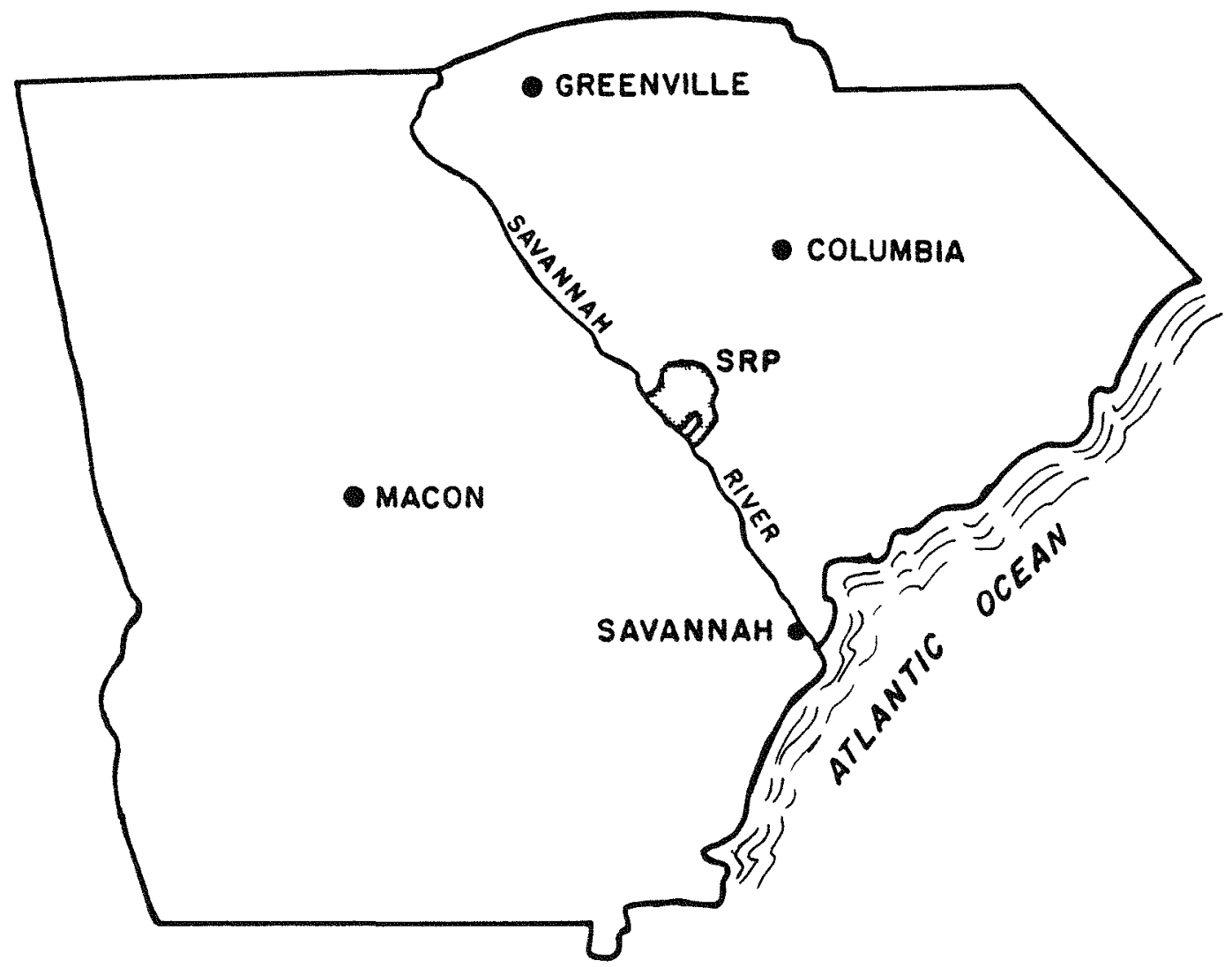

FIGURE 1. The Plant Location in South Carolina 


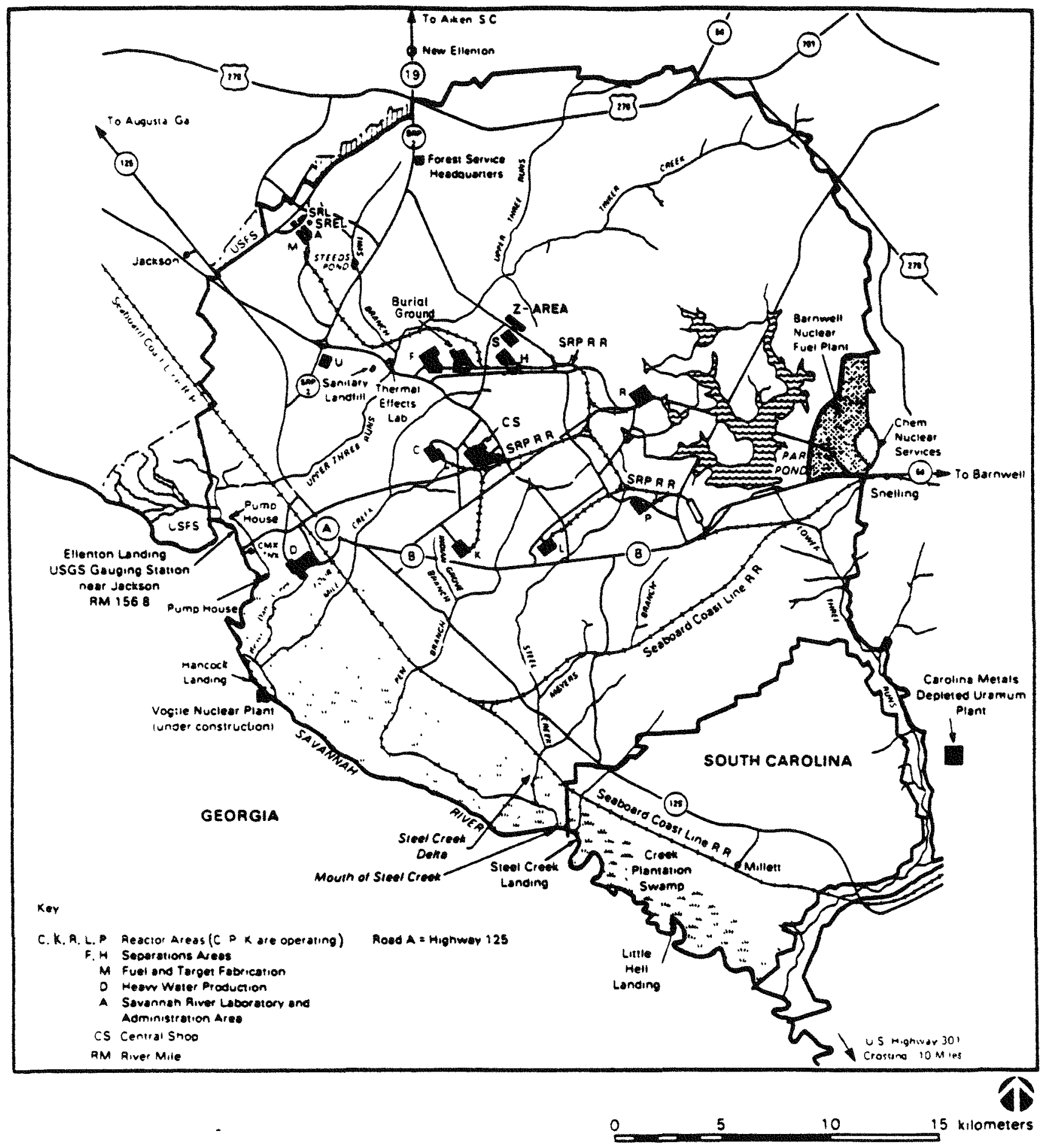

FIGURE 2. The Savannah River Plant site 


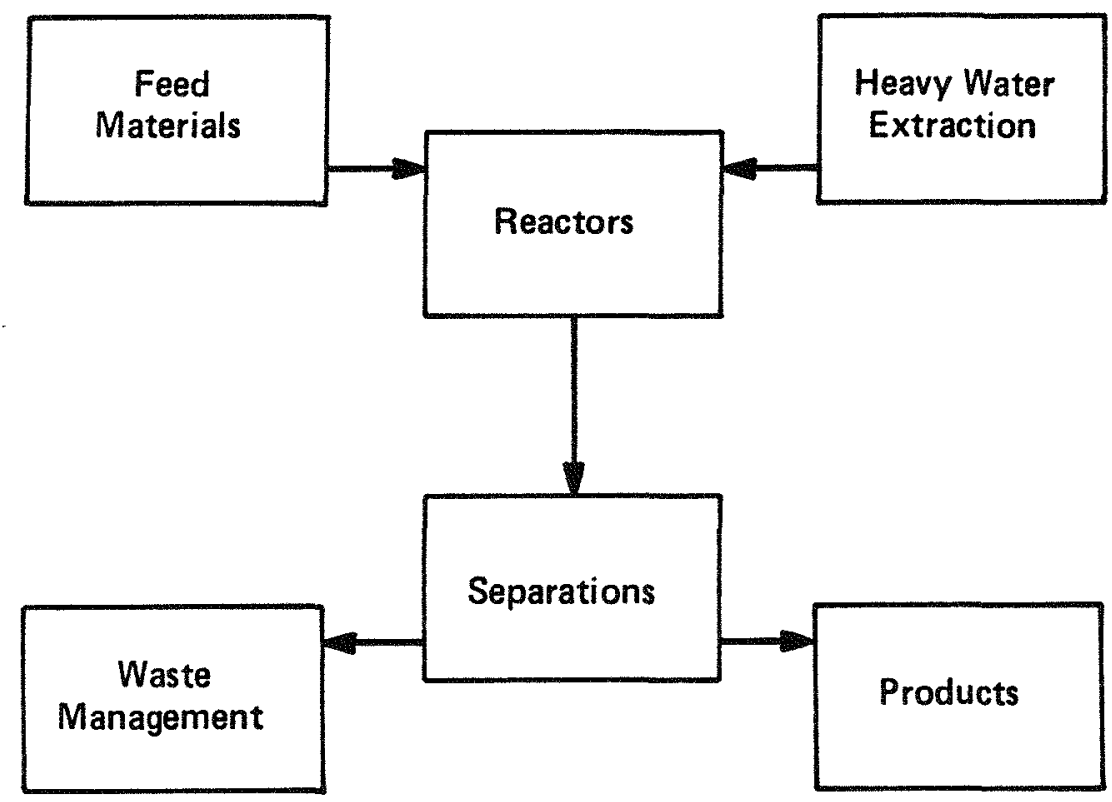

FIGURE 3. The Savannah River Production Complex 
- Management of the gaseous, liquid, and solid nuclear and chemical wastes

- Plus a host of support operations

Two new facilities will soon be in operation at Savannah River. The Defense Waste Processing Facility (DWPF) is being constructed to convert the radioactive material in the waste from the separations areas into a borosilicate glass matrix and to dispose of the salt solution, containing a small amount of radioactivity, as concrete monoliths. A Fuel Materials Facility (FMF) is also being constructed at SRP to produce fuel materials for the nuclear navy.

\section{BISTORY ${ }^{1-5}$}

The decision to build the Savannah River Plant was made by the United States Atomic Energy Commission early in 1950. The plant's mission, to produce materials for both nuclear and thermonuclear weapons, was dictated by the pressure of international tensions that developed as an aftermath of World War II. The decision followed by on 1 y a few months the successful testing by the Soviet Union of its first atomic weapon; that test was announced by President Truman on September 23, 1949. The Soviet Union's successful test intensified planning by the Department of Defense for a more diversified stockpile of nuclear weapons. Commission action was in response to this planning. 
A series of high level discussions and conferences was climaxed January 31, 1950, when President Truman directed the Atomic Energy Commission to continue work on all forms of atomic weapons, including production of materials for the so-called "Super," or hydrogen, weapon.

On June 12, 1950, the Commission asked Du Pont to undertake a new atomic project. Having designed, built, and operated the world's first plutonium production reactors and separations facilities at Hanford, Washington, in World War II, Du Pont had considerable know-how in nuclear operations. In 1946, with the war over, Du Pont asked to Government to release it from its Hanford assignment. For purely legal reasons, provisions had been made in the Hanford contract that Du Pont would receive a fee of one dollar for its Hanford assignment. Although the expected duration of the contract was stated, as is usual, soon after V-J Day, Du Pont was paid the entire fee of one dollar. This resulted in a disallowance by government auditors, since the entire time of the contract had not run out. Consequently, Du Pont was asked to return thirtythree cents to the United States. Fortunately, the officers of Du Pont had retained their sense of humor throughout their many years of association with the government and were able to derive considerable amusement from this ruling. The White House joined with the Commission in requesting Du Pont to assume the new task, to which Du Pont agreed on August 2, 1950. (The new contract was essentially the same as the Hanford 
contract; Du Pont was to receive no fee for the operation of the Savannah River Plant.) Previously, on June 29, the Commission had established a new Operations office with responsibility for all activities in connection with selection of a site for the new plant and the design, building, and operation of the new facilities. The office developed into the Savannah River Operations office, which administers the contract between the Government and Du Pont, on behalf of the Department of Energy, for operation of the Savannah River Plant and the Savannah River Laboratory.

\section{Selection of a site ${ }^{2}$}

The search for a site began in June, 1950. The Army Corps of Engineers assisted the Commission and Du Pont in locating the plant site and then acquired the land on behalf of the U. S. Government. Before a final decision was made, 114 potential sites in all sections of the country were examined, including locations in Georgia, Alabama, South Carolina, Minnesota, Arkansas, Texas, Wisconsin, Colorado, Mississippi, Missouri, Illinois, Rentucky, Louisiana, Nebraska, Oklahoma, Virginia, Tennessee, and North Carolina.

The criteria for the site selection demanded:

- Millions of gallons of water, low in mineral content, to remove the great quantities of heat that would be generated in the nuclear and chemical operations. 
- A large land area with terrain and topography conducive to fast construction, an area from which it would be necessary to remove a comparatively small number of people. It had to be somewhat isolated, yet near populated areas which could readily absorb construction and operations personnel.

- An area large enough to space the manufacturing facilities at distances which would best serve the interests of security and safety, and which also would meet special requirements of the Department of Defense.

- Accessibility, good transportation facilities, a low incidence of floods and storms, and a good labor market.

Selection of a site in South Carolina was recommended to the Atomic Energy Commission November 10,1950. The Department of Defense concurred.

Site Announced November 28, $1950^{2}$

On November 22, 1950, the Atomic Energy Commission in Washington formally approved selection of 250,000 acres in Aiken and Barnwell Counties, South Carolina--12 miles south of the City of Aiken and 15 miles southeast of the City of Augusta, Georgia. The historic Savannah River, which forms the area's southwestern boundary for 27 miles, was one of the most important keys to the final choice. The AEC at this time formally named the facility "The Savannah River Plant." 
There are five major streams and one smaller stream on the SRP site which are tributaries of the Savannah River. The five main streams are Upper Three Runs Creek, Four Mile Creek, Pen Branch, Steel Creek, and Lower Three Runs Creek; the small stream is Beaver Dam Creek. Upper Three Runs Creek is the largest natural SRP stream and is the only one with headwaters arising outside the plantsite. There are 127 miles of perennial streams and a total reservoir and lake area of 4500 acres.

Ellenton, population $600-$-the largest town--was destined to become the first incorporated community ever taken over by the U.S. Government for an atomic facility. Here also were Dunbarton, a village of 231, and several small communities--Hawthorne, Meyers Mil1, Robbins, and Leigh. In all, around 6000 persons, or about 1500 families, were relocated elsewhere in the interest of the national welfare.

The site selected lays in the inner margins of the coastal plains, has a subtropical humid climate, with an average growing season of 260 days. Since the installation of the Clark Hill Reservoir, the Savannah River flood plain is inundated an average of 75 days per year. Glaze (ice) storms may be expected about once every five years. Tornadoes are rare, but may occur.

The public received news of the site selection in a press release issued at noon on November $28,1950$.

On January 12, 1951, the project boundaries were realigned, removing the towns of Jackson, in Aiken County, and Snelling, in 
Barnwell County, from the site as originally announced, and reducing the area required by around 50,000 acres.

On May 15, 1952, the AEC announced it was acquiring certain properties on both banks of Lower Three Runs Creek extending southeast from the Plant site in Barnwell and Allendale Counties, South Carolina. Lower Three Runs is one of the natural drainage streams on the site used to discharge cooling water from manufacturing areas into the Savannah River. The acreage taken over along Lower Three Runs was 4,550 in Barnwell and Allendale Counties.

With the adjustment in site acreage, the original Savannah River Plant comprised 201,000 acres, or 315 square miles. The Savannah River Plant site has been adjusted over the years and today comprises 192,000 acres, or 300 square miles, spread over three South Carolina counties $(68,000$ acres in Aiken County, 121,000 in Barnwel1 County, and 4,000 in Allendale County).

The U. S. Government originally paid $\$ 19$ million for the site. As a note of interest, due to reforestation on the site, the SRP forest resource book value increased from an estimated $\$ 2$ million in 1952 to greater than $\$ 100$ million in 1986 . The cumulative sales of saw timber and pulpwood alone have been $\$ 22$ million (1955-July 1968). 


\section{Plant Construction ${ }^{2}$}

Construction of temporary facilities began February 1, 1951. Operations commenced with the startup of a unit of the heavy water extraction plant in D-Area on October 3, 1952. This was followed closely by uranium fuel fabrication in M-Area later that year. Criticality, or the beginning of reactor operations, in the first production reactor was achieved on December 28, 1953. The production reactors' startup schedule was as follows:

Reactor Startup Date

$\mathbf{R}$ Dec 1953

$\mathbf{P}$ Feb 1954

L Jul 1954

$\mathrm{K}$ Nov 1954

C Mar 1955

R Reactor was placed on standby in June 1964 and L Reactor was placed on standby in February 1968. L Reactor has been refurbished and was returned to operation during October 1985.

Construction of the first Separations Area was essentially complete late in 1953, and processing of radioactive fuel assemblies from the reactor areas began in November 1954 in F-Area and July 1955 in H-Area. Between March 1957 and March 1959, modifications were made to the F-Area separations plant to expand the processing capacity from $\sim 3$ to 15 metric tonnes of uranium per day. During the F-Area upgrade, a new plutonium finishing facility was constructed atop the solvent extraction facility. 
Construction of the basic plant was completed in 1956 at a cost of more than $\$ 1.1$ billion, including the land. Facts on the initial construction of the Savannah River Plant are given in Table 1. OPERATIONS 1-3 $^{-3}$

The plant's primary mission is the production of plutonium, tritium, and other special nuclear materials. These nuclear materials are produced by transmutation of elements in large nuclear reactors that are moderated and cooled by heavy water. Materials produced in the SRP reactors are first separated and purified and are then sent to other DOE installations for fabrication into weapon components or for use in various peacetime atomic projects. The production process is shown schematically in Figure 4.

\section{Feed Materials 2,3}

The fuel of the atomic age is uranium, the heaviest element found on earth in any appreciable quantity. Never found alone in nature, uranium must be purified before use.

During World War II, the United States used uranium from mines in Canada and the Belgian Congo (now Zaire).

Today, the United States' principal source of uranium is the Colorado Plateau, 130,000 square miles of rainbow colored rock where Colorado, Utah, Arizona, and New Mexico meet. This uranium was concentrated millions of years ago. Today, the canyon walls of the Colorado Plateau, carved by rushing rivers, 
TABLE 1

Facts on Initial Construction of the Savannah River Plant

Earth Moved

$39,150,000$ cubic yards; equal to a wall 10 feet high and 6 feet wide from Atlanta, Georgia, to Portland, Oregon. This is approximately $1 / 6$ the $220,538,000$ cubic yards required in digging the Panama Canal.

Concrete

$1,453,000$ cubic yards; equal to a highway 6 inches thick and 20 feet wide from Atlanta, Georgia, to Philadelphia, Pennsylvania. This is approximately $1 / 3$ the total concrete poured $(4,400,000$ cubic yards) in the Grand Coulee Dam.

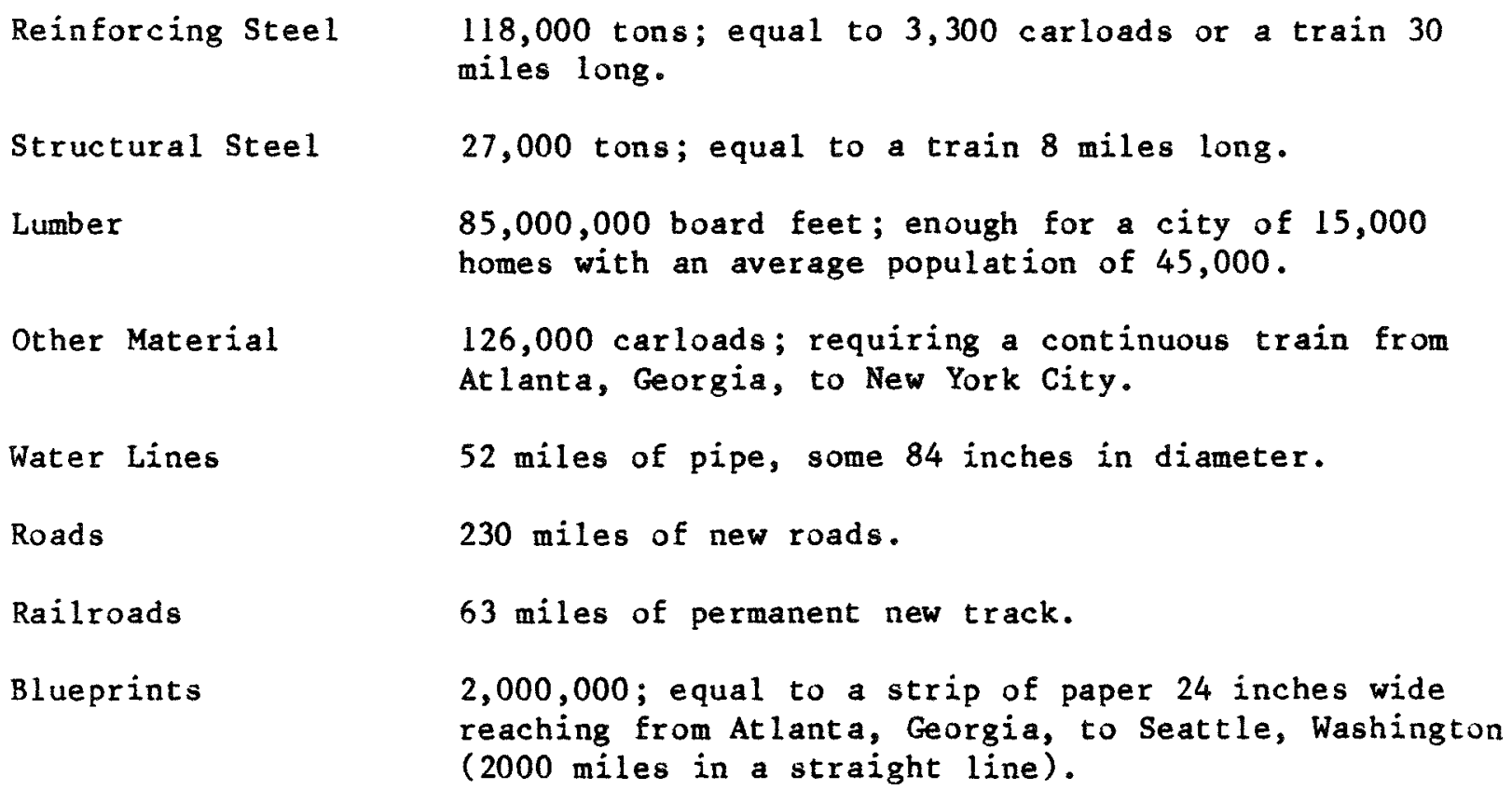

Permanent Buildings 280 . 
FUEL ELEMENTS, BARE URANIUM

"SLUGS", COME TO THE PLANT

FROM OFFSITE SUPPLIERS

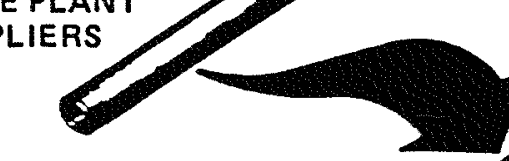

THE "SLUGs" ARE THEN

ENCASED IN ALUMINUM

JACKETS

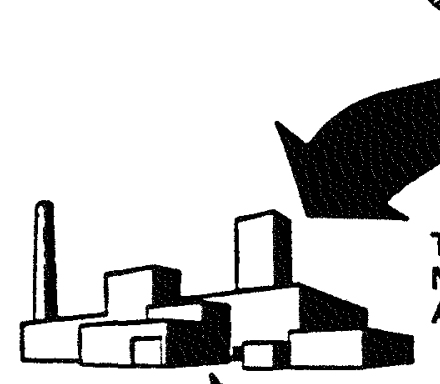

THE "SLUGS" ARE NEXT TAKEN TO THE NUCLEAR REACTORS WHERE THEY ARE IRRADIATED BY NEUTRONS

AFTER THE IRRADIATION PROCESS, THEY ARE STORED IN WATER FOR A PERIOD OF TIME TO COOL OFF AND LATER TAKEN TO THE CHEMICAL SEPARATIONS PLANT FROM WHICH FLOWS-

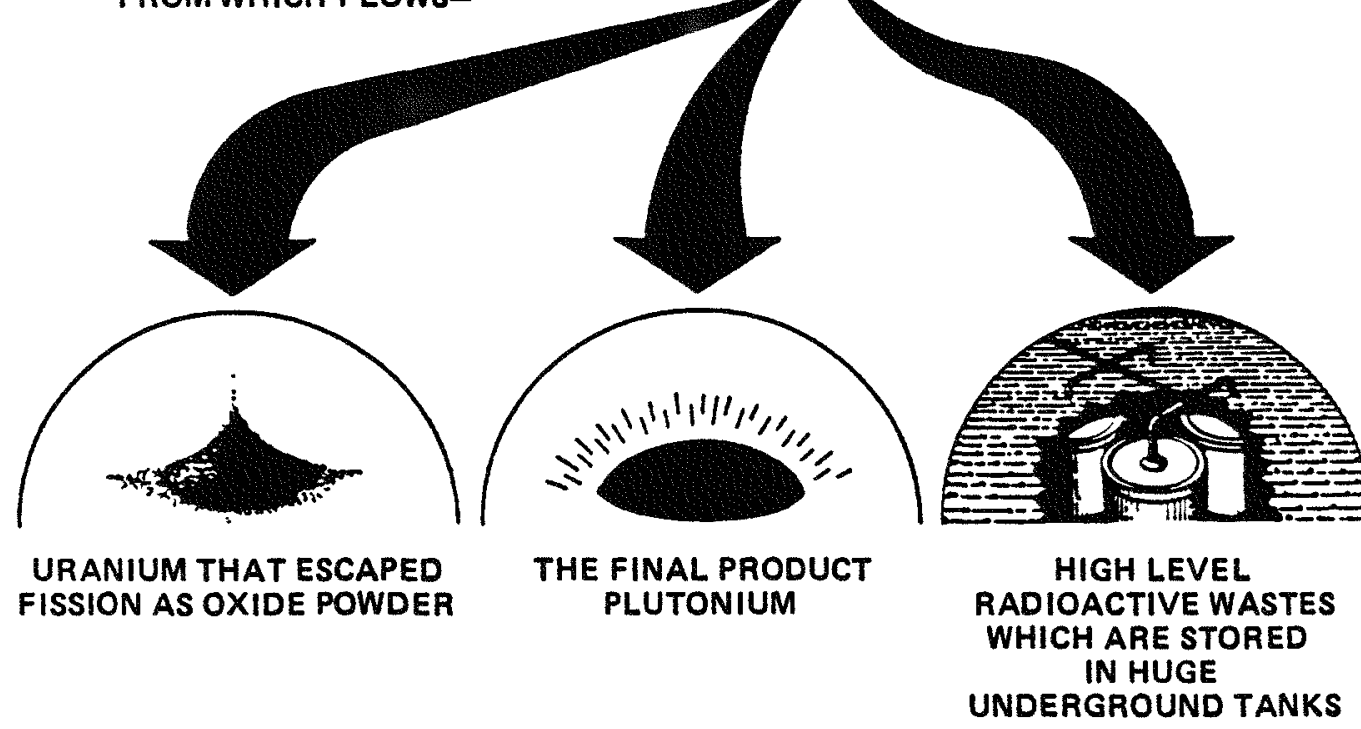

Similar procedures are followed in the production of californium-252, plutonium-238, cobalt-60 and curium-244.

FIGURE 4. The Plutoniu Production Process 
reveal the sediment laid down in past geologic time. Ancient plains containing uranium ore lie frozen in bands of red and gray. Where there is uranium, there is radiation, and prospectors use special radiation detection instruments (Geiger-Muller counters) to locate deposits. The uranium ores are mined, crushed, and roasted. A ton of ore yields about 10 pounds of uranium.

After further treatment, high grade concentrates are processed in special refining plants. The uranium is then shipped to gaseous diffusion plants for enrichment of the $235 \mathrm{U}$ isotope prior to use in nuclear reactors.

A pound of natural uranium $\left(0.71 \%^{235} \mathrm{u}\right)$ has the potential energy of $3,000,000$ pounds ( 1500 tons) of coal. This is equivalent to approximately 20 carloads of coal.

Any given amount of natural uranium is substantially composed of two kinds of uranium atoms, one having a weight of 235 (which means it is 235 times heavier than the simple hydrogen atom, nature's lightest element) and another having a weight of 238 .

The uranium-235 atoms comprise but $7 / 10$ of one percent of the total in any given amount of naturally occurring uranium. They are the ones, however, which split, or fission, when a mass of uranium is brought together under certain conditions. The rest of the uranium, or 99.3 percent, is uranium-238. 


\section{Fuel and Target Fabrication 2,3}

The Savannah River reactors were originally charged with natural uranium fuel. However, they are now charged with a combination of enriched uranium fuel and depleted uranium targets.

The fuel, which has been enriched in the fissionable isotope U-235 in the gaseous diffusion process at Oak Ridge, Tennessee, is shipped by truck in special containers to the Savannah River Plant where it is melted and alloyed with pure aluminum. The casting is then simultaneously sheathed with aluminum and formed into long thin tubes by a "co-extrusion" process developed at the Savannah River Plant.

Targets are fabricated from depleted uranium for production of plutonium-239. This material is obtained from DOE facilities in Fernald, Ohio. At Fernald, the depleted uranium metal is turned into hollow, cylindrical forms called "slugs." These "slugs" of bare uranium metal eight inches long are sent to the Savannah River Plant (Figure 5).

In the Raw Materials Area at the Savannah River Plant, the uranium metal in tubular form is clad with aluminum jackets (Figure 5). Cladding protects the uranium metal from corrosion by the heavy water coolant in the reactors and confines the highly radioactive "fission products," as well as the product plutonium formed in the slugs by reactor exposure. 


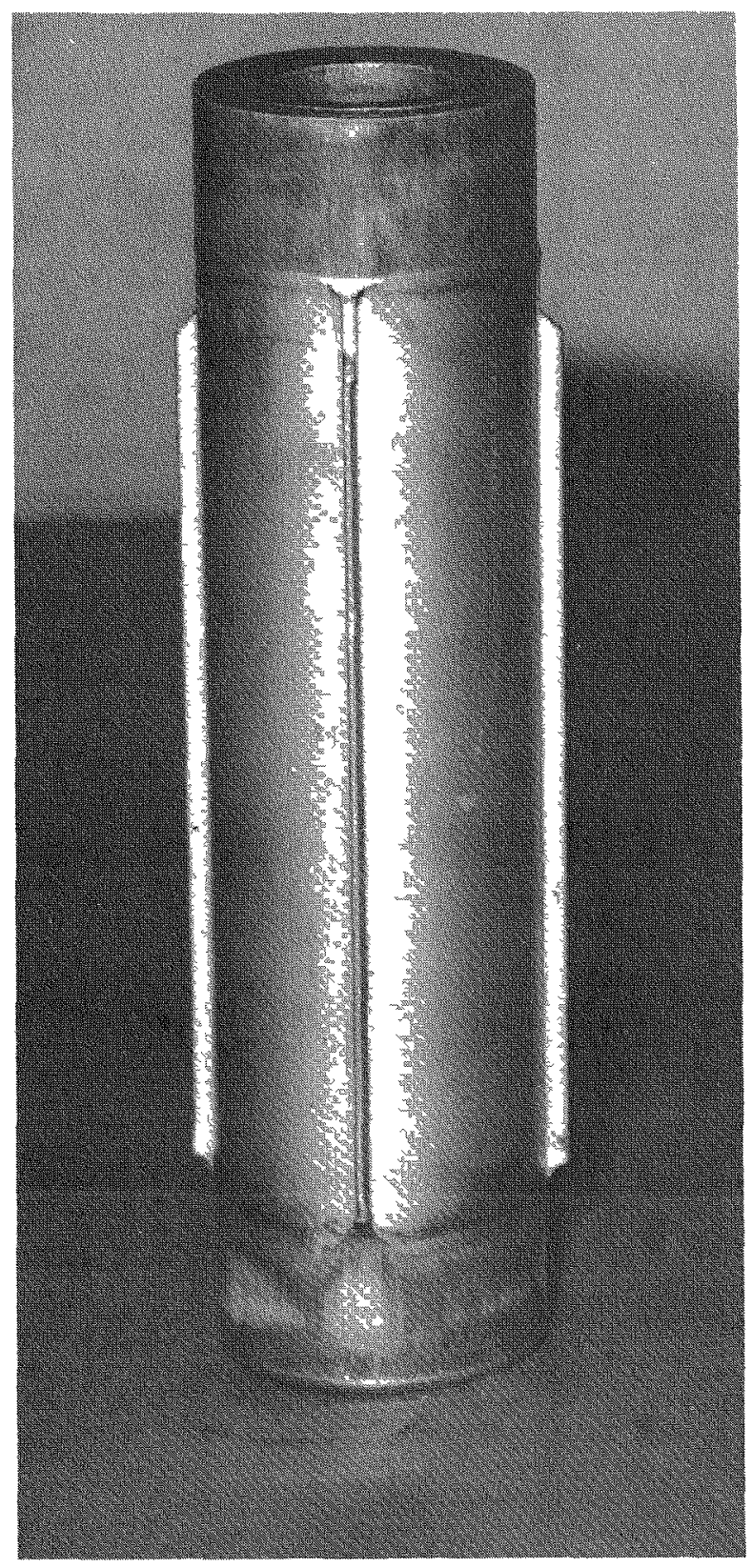

FIGURE 5. Uranium Target Slugs 
Reactor control rods and "target" elements required for the

production of various isotopes such as ${ }^{238} \mathrm{Pu},{ }^{243} \mathrm{Am},{ }^{244} \mathrm{Cm}, 252 \mathrm{Cf}$, etc. must be clad with aluminum in the Raw Materials Area before reactor exposure.

To minimize costly failures during reactor operation, extensive inspections and tests are performed on all fabricated materials to ensure integrity before they are classified "reactor acceptable."

\section{Reactor Operations $2,3,6$}

The Savannah River reactors (Figure 6) are essentially alike. Each reactor (Figures 7 and 8 ) consists of a large shielded stainless steel tank filled with heavy water. Inserted into the heavy water are many columns of fuel and target elements in specified configurations. Heat generated by nuclear fission is removed by circulating heavy water in a closed loop past all fuel elements, through external heat exchangers, and back into the reactor.

The heavy water that flows through tubes in the heat exchangers is cooled by river water which flows simultaneously through the exchangers. The heated river water is discharged to tributaries of the Savannah River or to large cooling ponds. Most of the heat is dissipated before the water returns to the river. During reactor operation, neutrons cause uranium-235 atoms to fission into lighter atoms called "fission products." In addition, 


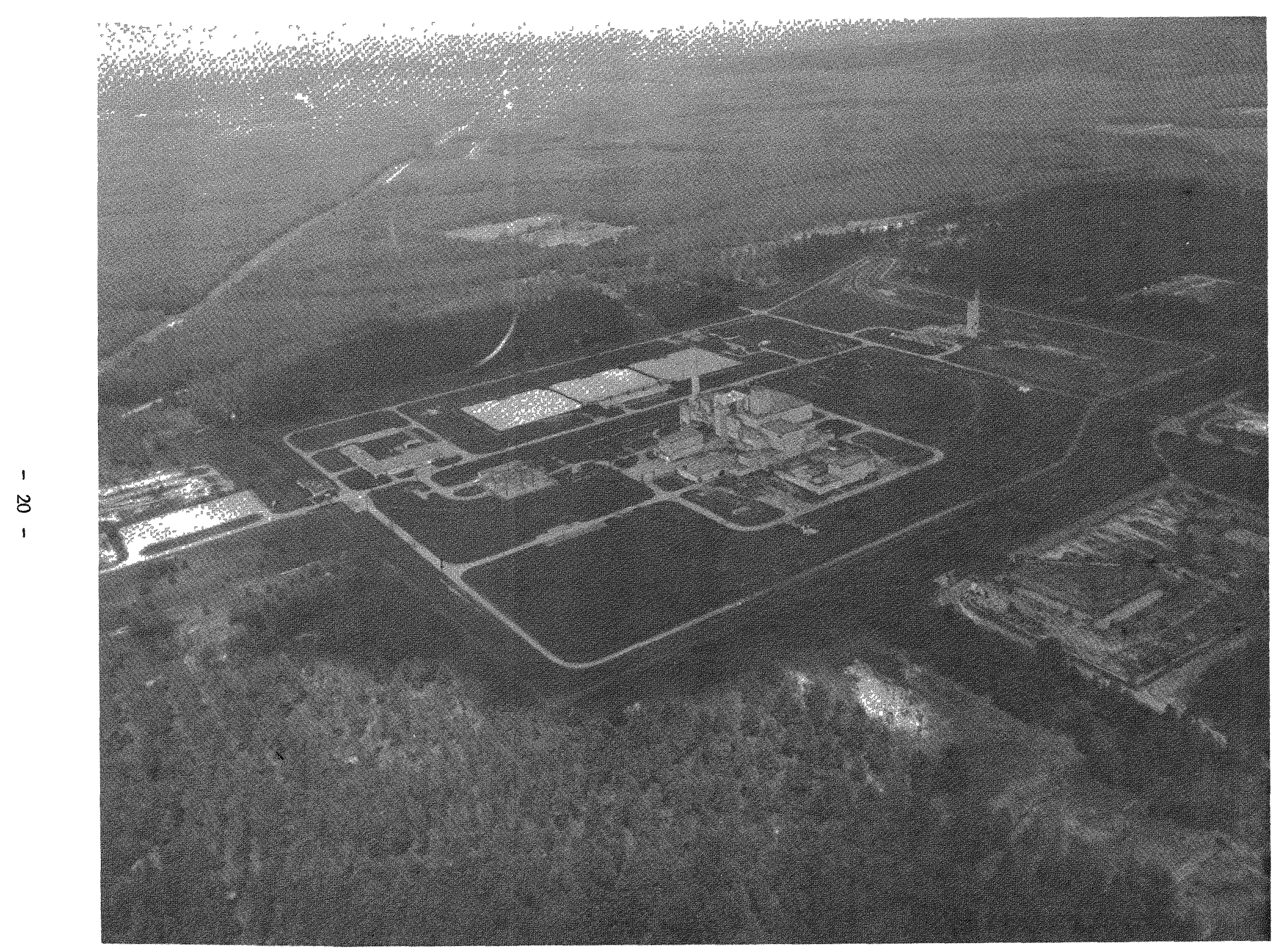

FIGURE 6. An SRP Reactor Area

, 


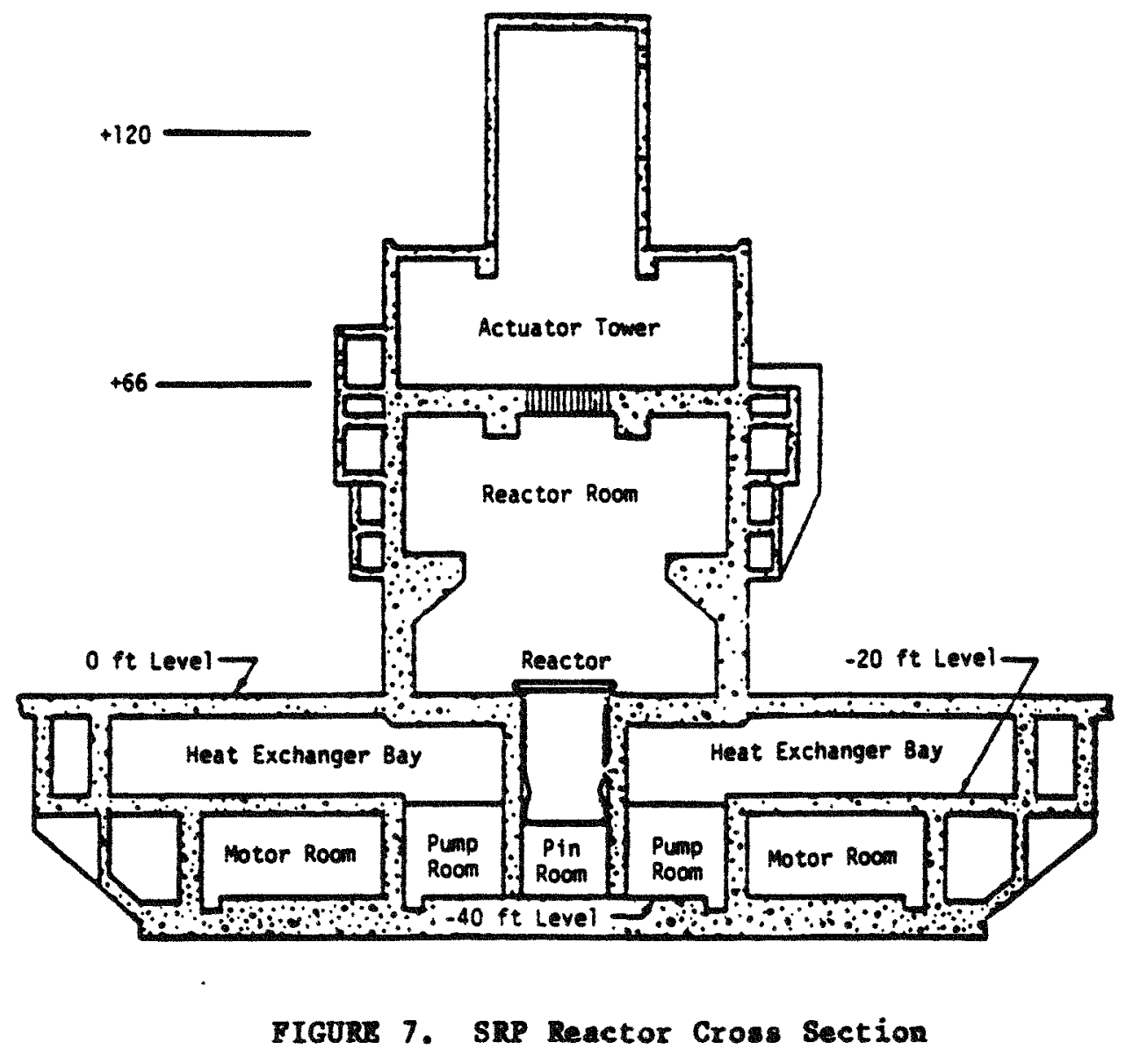




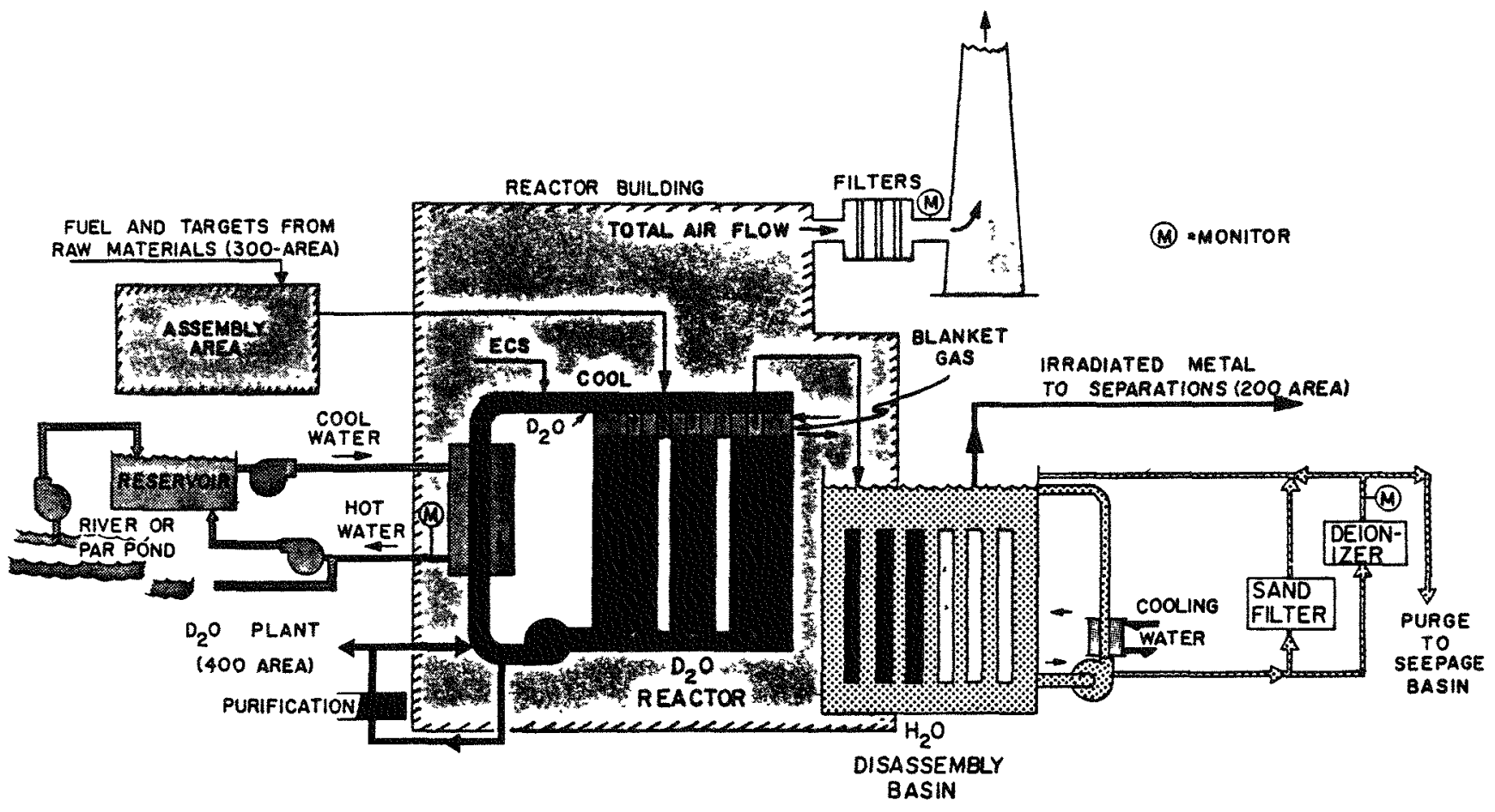

FIGURS 8. SRP Reactor Proces Systen 
each atom fissioned releases two to three neutrons, thereby multiplying the supply of neutrons in the reactor (see Figure 9). This multiplication results in a chain reaction that generates enormous amounts of energy. Heavy water in the reactor removes the heat produced and also acts as a moderator which slows the neutrons down to facilitate their capture by other atoms.

Some neutrons from the uranium-235 chain reaction change the uranium-238 atoms. A neutron captured by a uranium-238 atom transforms it to uranium-239, an artificial and unstable uranium isotope. The uranium-239 atom emits a beta particle to form neptunium-239, which in turn emits another beta particle to form plutonium-239, which is more fissionable than uranium-235.

The production of plutonium can then be represented by the following reactions:

${ }^{235} \mathrm{U}+$ slow neutron $\longrightarrow$ fission products + fast neutrons + radiation

fast neutrons + moderator $\longrightarrow$ slow neutrons 


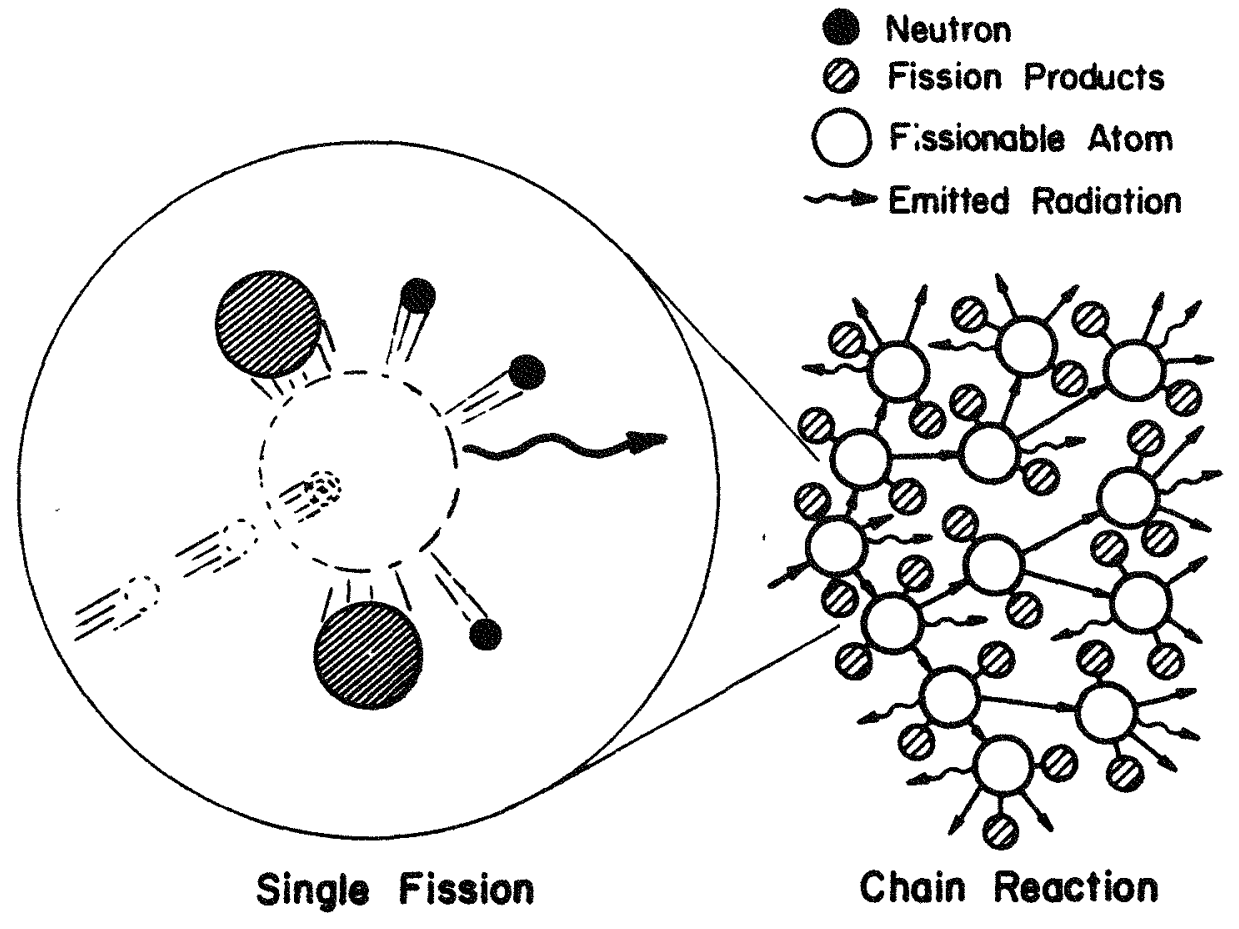

PIGURE 9. Depiction of chain Reaction 
slow neutrons $+{ }^{238} U \longrightarrow{ }^{239} U+$ gamma

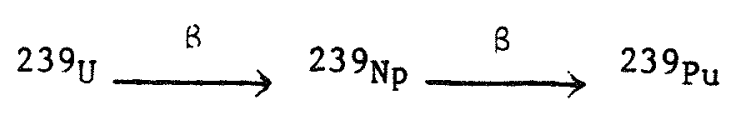

Plutonium-239 can also capture a neutron, which transforms it to plutonium-240. In like manner, a neutron capture by a plutonium-240 atom transforms it to plutonium-241. The specific mix of isotopes obtained from a reactor then is governed by the length of time a target element is exposed to the controlled fissioning process. After a designated period, the fuel and target elements are removed by remote control into a large pool of water in the reactor building to permit decay of short lived fission products before the elements are delivered to a chemical separations plant.

The decay period for nuclear fuels prior to their reprocessing is governed by two considerations: (1) decay of the heavy element chains, principally ${ }^{237} \mathrm{U}$, and (2) decay of fission products, principally ${ }^{131} \mathrm{I}$ and ${ }^{133} \mathrm{Xe}$ in the early stages of cooling. ${ }^{235} \mathrm{U}$, by successive neutron captures, is converted to ${ }^{237} \mathrm{U}$ (Equation 5).

$$
235 \mathrm{U}+\text { neutron } \longrightarrow 236 \mathrm{U} \longrightarrow{ }^{237 \mathrm{U}} \stackrel{\cdot}{B}^{237 \mathrm{~Np}}
$$

6.7 days 
${ }^{237} \mathrm{U}$ is a beta emitter of high energy and since the recovered uranium is to be handled by direct contact, ${ }^{237} \mathrm{U}$ must have been allowed to decay sufficiently for it to present no radiation hazard. Ten half-lives ( 67 days) reduce the radiation by a factor of $10^{3}$; twenty half-lives ( 134 days) reduce the radiation by a factor of $10^{6}$.

The amount of decay of fission products that must precede reprocessing will be governed by two factors: (1) the radiation dosage that can be tolerated in the chemical process and (2) the radiation level tolerated in the recovered products. Shorter cooling times require more extensive decontamination since the recovered fuel is to be handled directly. Generally, the matter of cooling time, recovery of fissionable material, cost of processing, and cost of holding fuel material in inventory are all factors in the highly complex system of fuel processing.

\section{Chemeial Separations}

\section{overview 7}

Reactor products are recovered in chemical separations areas. Plutonium, now present in the discharged depleted uranium targets as a result of transmutation, must be extracted from the uranium and freed from fission products which emit intense gamma radiation.

Figure 10 illustrates, in very brief fashion, the essentials of the flow of materials from the reactors through the separations 


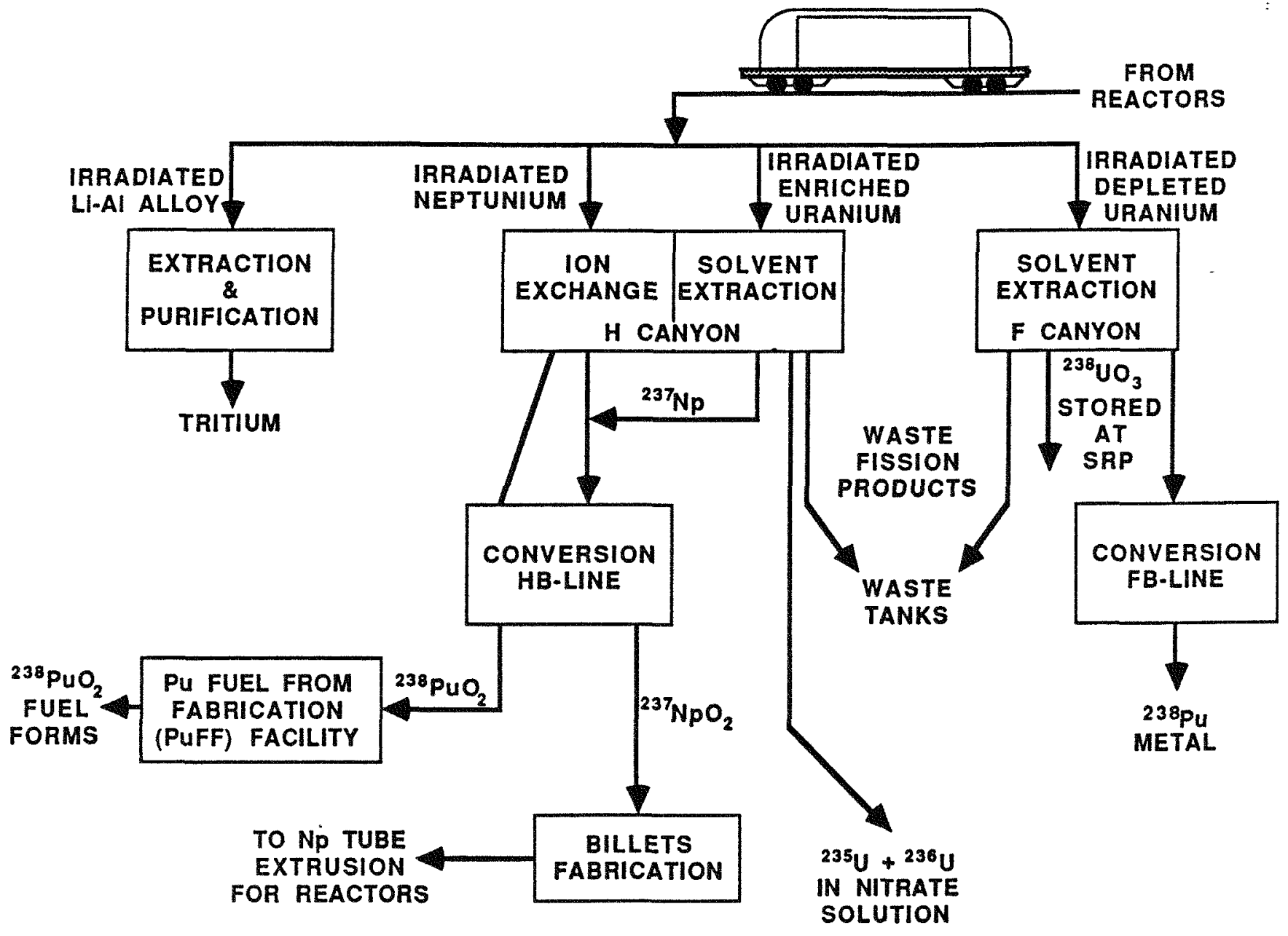

FIGURE 10. Overview of Chemical Separations 
area. Depleted uranium targets are processed through the F-Area facilities solvent extraction process. Enriched uranium fuel elements are processed through the H-Area canyon by a modification of the F-Area solvent extraction process. Irradiated neptunium targets are processed for recovery of Pu-238 through the H-Area canyon by an ion exchange process.

Following receipt of the irradiated depleted uranium targets in the F-Area Separations Area, aluminum cladding is chemically removed by dissolution with a $\mathrm{NaNO}_{3}-\mathrm{NaOH}$ solution and sent to waste storage. The bare uranium targets are then dissolved in boiling $10 \mathrm{M} \mathrm{HNO}_{3}$. Solvent extraction technology is used to separate and purify both the plutonium and the uranium. The purified uranium solutions are concentrated by successive evaporation steps first to $\mathrm{UO}_{2}\left(\mathrm{NO}_{3}\right)_{2} \cdot 6 \mathrm{H}_{2} \mathrm{O}$ and then thermally denitrated to $\mathrm{UO}_{3}$. The purified plutonium solutions are concentrated by cation exchange and precipitated as $\mathrm{PuF}_{3}$. The precipitate is roasted in an oxygen atmosphere where the plutonium is oxidized to a mixture of 73 mole \% PuF 4 and 27 mole \% $\mathrm{PuO}_{2}$ (the theorecical ratio is $75 \%$ to $25 \%$ ). The mixture then undergoes a calciothermic reduction to plutonium metal prior to shipment offsite. Waste solutions from these processes which contain residual plutonium and small amounts of neptunium are processed through an anion exchange system to recover both the plutonium and neptunium. The waste streams are evaporated, acid stripped, and adjusted to $\mathrm{pH}>13$ by addition of $\mathrm{NaOH}$ before storage in underground mild steel double-shell tanks. 
Following receipt of the spent enriched uranium fuel in the $\mathrm{H}$-Area canyon, this aluminum clad $\mathrm{Al}-\mathrm{U}$ alloy is dissolved in $\mathrm{HNO}_{3}$ catalyzed with $\mathrm{Hg}\left(\mathrm{NO}_{3}\right)_{2}$. The dissolver solution is frequently blended with dissolved offsite fuels such as research reactor fuels from various universities and High Flux Isotope Reactor (HFIR) cores from Oak Ridge before the uranium and neptunium are separated and purified using a modified Purex process. The purified $\mathrm{UO}_{2}\left(\mathrm{NO}_{3}\right)_{2}$ solution is shipped offsite for conversion to uranium metal. This uranium metal is then recycled back to the Savannah River $P$ lant and used in fuel tubes for the SRP reactors. Since this uranium is repeatedly recycled through the reactors, the $236 \mathrm{U}$ content has increased over the years. The neptunium, produced in the fuel tubes by the irradiation of the ${ }^{236} \mathrm{U}$, is concentrated by anion exchange, precipitated as an oxalate, and calcined to the oxide. This $\mathrm{NpO}_{2}$ is then fabricated into aluminum $\mathrm{clad} \mathrm{NpO}_{2}$-aluminum cermet targets via a powder metallurgical process and returned to the reactors to produce plutonium-238.

Irradiated neptunium targets are received in $\mathrm{H}-\mathrm{Canyon}$ and dissolved in $\mathrm{HNO}_{3}$ catalyzed with $\mathrm{Hg}\left(\mathrm{NO}_{3}\right)_{2}$. The $237 \mathrm{~Np}$ and ${ }^{238} \mathrm{Pu}$ are then purified and partitioned from each other by two cycles of anion exchange. Both products are further purified by anion exchange, precipitated as oxalates, and calcined to oxides. The purified ${ }^{238} \mathrm{PuO}_{2}$ is fabricated into heat sources for thermoelectric generators used in the nation's space program. 
The waste streams from the H-Area processes are also evaporated, acid stripped, and adjusted to $\mathrm{pH}>13$ by addition of $\mathrm{NaOH}$ before storage in underground double shell tanks.

The Savannah River Plant also processes other targets to produce nonroutine specialty isotopes, a wide variety of fuels from offsite research reactors, and a wide range of unirradiated plutonium scrap materials. Following customary Savannah River practice, initial processing of each offsite material is designed to transform the actinides (primarily uranium, neptunium, and plutonium) to a solution that is compatible with one of the solvent extraction cycles in either of the separations areas. A major advantage of this practice is that the uranium and plutonium isotopes can be blended over a wide range. Since the actinide can be introduced to the mainline process at several different points, a greater range of contaminants can be handled by routine operations. This simplifies many of the initial purification steps over those that would be required if only one entry point were available.

\section{Process Buildings}

\section{Canyon 4,8}

The initial separations and purification operations, including receipt of targets, dissolving, feed clarification, solvent extraction; and waste handling, are performed remotely in a concrete shielded building called the "canyon" building 
(Figure 11). The building is $255 \mathrm{~m}$ ( $850 \mathrm{ft}$ ) long, $37 \mathrm{~m}$ (122 ft) wide, and $20 \mathrm{~m} 66 \mathrm{ft}$ ) high. Figure 4 shows a cross section of the building. The "hot" canyon, shown on the right, contains the processes for the most radioactive materials (dissolving, high activity waste processing, and the first cycle of solvent extraction). The "warm" canyon contains the second solvent extraction cycles, low activity waste processing, and some recycle operations.

Operations within the process building utilize conventional industrial techniques; however, the nature of materials handled required unusual features of design and construction. Shielding from materials in the process required a massive, windowless, reinforced concrete construction. Because of radioactivity and airborne contamination hazards, special precautions were taken in the internal building arrangement. Ventilation comes from two independent systems, one for personnel areas and one for the canyons. A pressure differential is maintained to ensure airflow toward contaminated areas under normal and emergency conditions. The building consists of seventeen $13.1-\mathrm{m}(43-\mathrm{ft})$ sections and one $25.9 \mathrm{~m}$ ( $85 \mathrm{ft}$ ) section. The pattern of embedded piping is duplicated over each section along the length of the canyon, that is, each section is an exact replica of all other sections in locations of tank positioning guides and wall nozzles. This arrangement provides valuable flexibility to accomnodate process changes. 


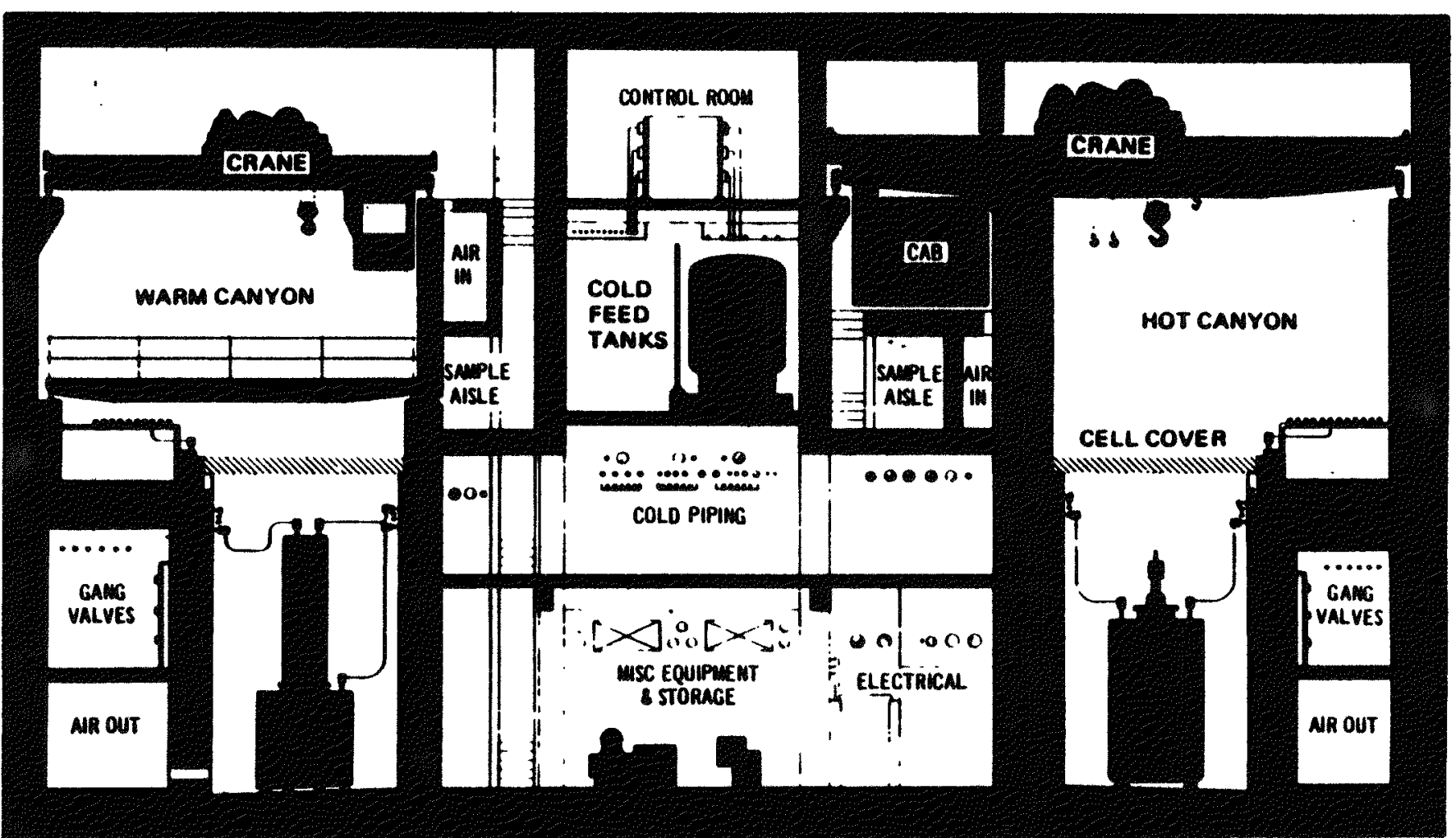

PIGURE 11. Crose Section of Separations Building 
The hot canyon is serviced by a $50,800-\mathrm{kg}(50-\mathrm{t})$ capacity rail mounted bridge crane remotely operated from a shielded cab behind concrete (Figure 11). The operator views the canyon equipment through a remote optic system that has three powers and traverses the canyon. The bridge crane is equipped with several hooks and impact wrenches. All equipment is moved by the use of specially designed yokes that are stored in the canyon. The bridge crane that services the warm canyon is similar except that it is operated from a shielded gondola cab in which the canyon equipment is viewed directly. A partial view of the warm canyon with cell covers removed is shown in Figure 12.

\section{Plutonium Finishing ${ }^{16}$}

That portion of Building 221-F which houses the plutonium metal finishing facility was built either as part of the original construction during 1951-1953 (third and fourth levels) or as part of the F-Area upgrade construction during 1957-1958 (fifth and sixth levels). The outside dimensions of the finishing line two-story addition (fifth and sixth levels) are 129 feet long by 67 feet wide, and the single-story extension (fifth level) is approximately 35 feet wide by 20 feet long. The total height of the finishing line is 93 feet above grade level.

Plutonium streams which contain little fission product activity do not require the shielding of the initial high activity solutions, but because of the toxicity of plutonium, all lines and 


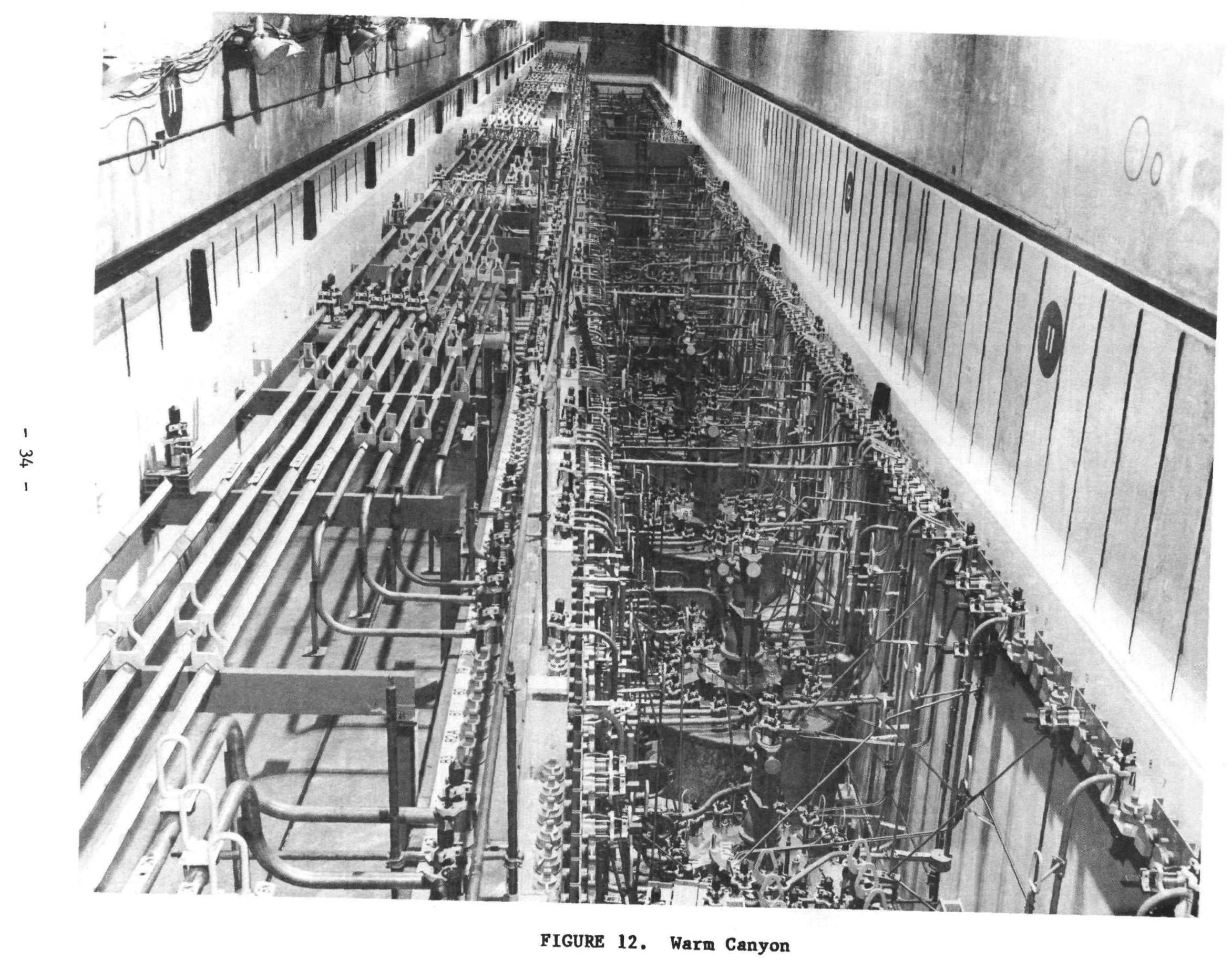




\begin{abstract}
vessels are enclosed in ducts and plastic panelled cabinets and glove boxes. The cabinets and glove boxes house the cation exchange, precipitation, and reduction equipment. All hands-on operations are done through gloves attached to the enclosures. The vessels are maintained at a differential of about 2 inches of $\mathrm{H}_{2} \mathrm{O}$ below the pressure in the room. These conditions, maintained by using separate exhaust systems for the cabinets and the vessel vents, ensure that all leaks will result in air flows away from operating personnel. All air from vessles, cabinets, and rooms is filtered through high-efficiency particulate air filters (HEPA) and monitored. It is then discharged to the sand filter for further filtration before being discharged to the environment from a 200-foot stack.
\end{abstract}




\section{Solvent Extraction Process}

The Basic Purex Process Chemistry $1,5,9-11$

The name "Purex" was derived at Knolls Atomic Power Laboratory (RAPL) from Plutonium Uranium Recovery by Extraction. The extractant was tri-n-butyl phosphate (TBP), which has proved to be an excellent choice. (The physical properties of TBP are given in Table 2). In fact, after more than 30 years of operations, no other extractant is being considered seriously for processing irradiated commercial fuel anywhere in the free world. TBP has good radiolytic and chemical stability and low aqueous solubility. Its complexing properties make it possible not only to efficiently eliminate the undesired fission products and other actinide byproducts (i.e. americium, curium, and thorium), but also to cleanly separate the desired products--uranium, plutonium, and neptunium--from each other.

The Purex process (Figure 13) as practiced at Savannah River is a counter-current solvent extraction process which uses a solution of TBP in a non-polar organic diluent. The percentage of TBP in the solvent used in the various Purex modifications for different applications at SRP has been $3.5 \%, 7.5 \%, 10 \%, 30 \%$, and $50 \%$. The diluents used at SRP have been refined kerosene and various n-paraffin oils. At SRP, various Purex modifications have been used to process fuels and targets varying in $235 \mathrm{U}$ enrichment from $0.2 \%$ to over $93 \%$ and recover the transmutation products 
TABLE 2

Physical Properties of Tri-n-Butyl Phosphate

\section{Property}

Color
Density
Dielectric Constant $\left(25^{\circ} \mathrm{C}\right)$
Flashpoint (Cleveland Open Cup)
Melting Point
Solubility in Water (g/1iter)
Refractive Index (ND)
Concentration of $\mathrm{N}_{3}$ (moles/1iter)
0.00
0.79
1.97
4.01
6.41
9.61
12.00
13.80
15.60
100.00

Viscosity $\left(25^{\circ} \mathrm{C}\right)$

Water Solubility in TBP (g/liter)

Solubility in Organic Solvents
Value

Colorless

$0.973 \mathrm{~g} / \mathrm{cc}$

8.13

$145^{\circ} \mathrm{C}$

No definite melting point to $-197^{\circ} \mathrm{C}$

(Passes into a glassy state)

0.39 (Decreases with increasing temperature)

1.4225

Solubility of TBP (g/liter)

$$
\begin{gathered}
0.39 \\
0.36 \\
0.31 \\
0.24 \\
0.16 \\
0.17 \\
0.29 \\
0.61 \\
1.56 \\
\text { Completely Miscible }
\end{gathered}
$$

$33.2 \mathrm{mP}$

64 (Changes little with temperature)

Completely miscible at ordinary temperatures with all comon organic solvents 


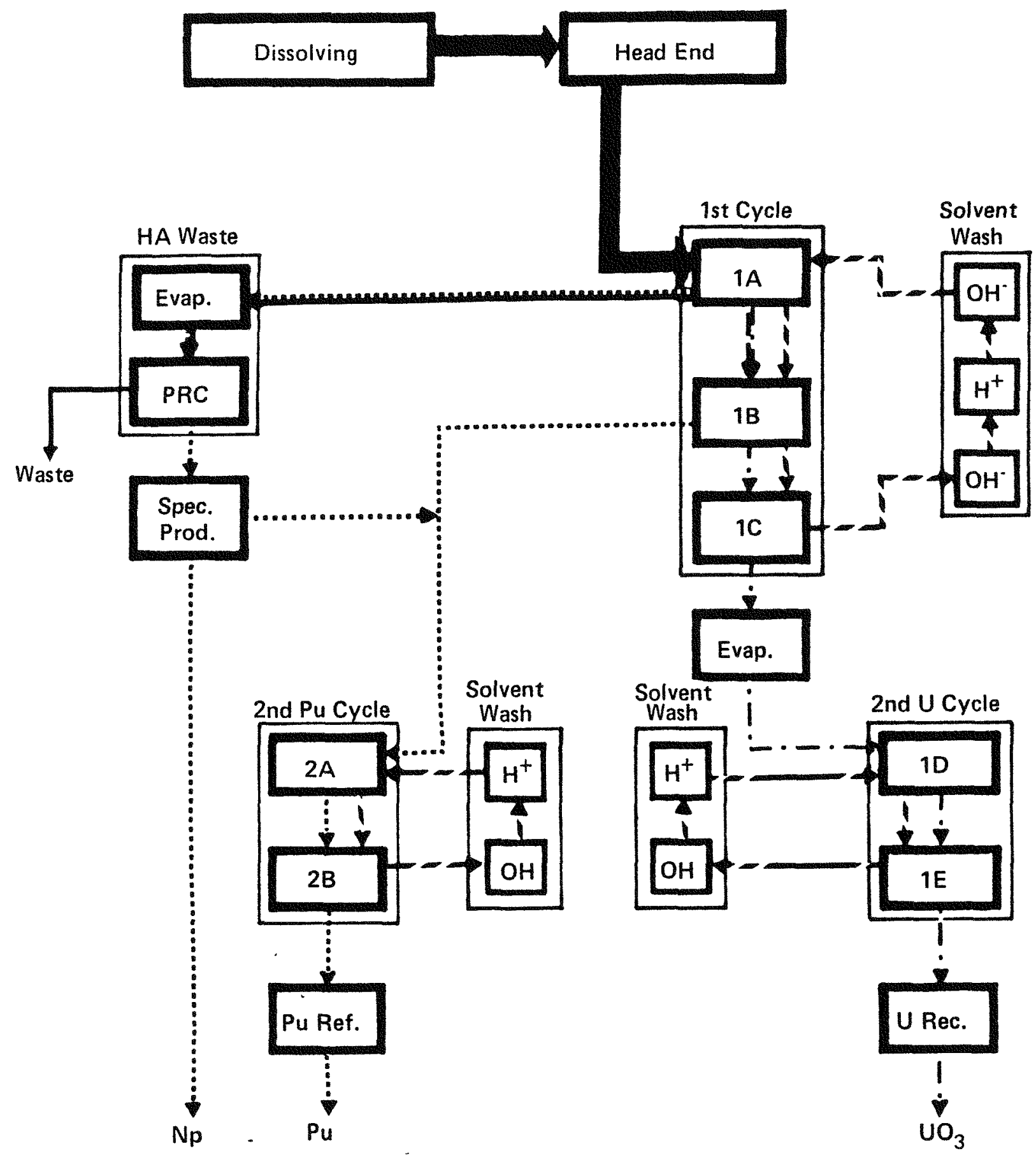

FIGURE 13. The Purex Process at SRP 
plut onium-239 and neptunium-237. Each of the three solvent cycles has its own segregated solvent system, including solvent washing. Typical Purex feed contains uranyl nitrate, nitric acid, plutonium(IV) nitrate, fission products, and small concentrations of actinide byproducts. The first cycle of solvent extraction provides the initial decontamination from fission products (Figure 14) and the separation of plutonium and uranium. In the first "bank," the plutonium and uranium are extracted into the solvent as $\mathrm{Pu}\left(\mathrm{NO}_{3}\right)_{4}(\mathrm{TBP})_{2}$ and $\mathrm{UO}_{2}\left(\mathrm{NO}_{3}\right)_{2}(\mathrm{TBP})_{2}$. The solvent from the first bank contains the desired products and becomes the feed for the second bank. Neptunium byproduct can be rejected to the aqueous "waste" (1AW) stream by feeding a small stream of nitrous acid or nitrite salt solution into the bank to keep the neptunium in the inextractable $\mathrm{Np}(\mathrm{V})$ valence. Both neptunium and plutonium rejected to the IAW are recovered using agitated bed anion exchange column, i.e. the primary recovery column (PRC).

In the second bank (1B bank in SRP's nomenclature), the uranium-plutonium separation is accomplished by reducing plutonium to the inextractable Pu(III) oxidation state, and stripping it from the solvent into the aqueous IBP stream. In the third bank of the first cycle, the IC bank, the uranium is stripped from the solvent into a low acid stream, $1 \mathrm{CU}$.

Thus, four streams exit the first cycle: (1) the spent solvent, $1 \mathrm{CW}$, which is washed and recycled; (2) the aqueous waste, 


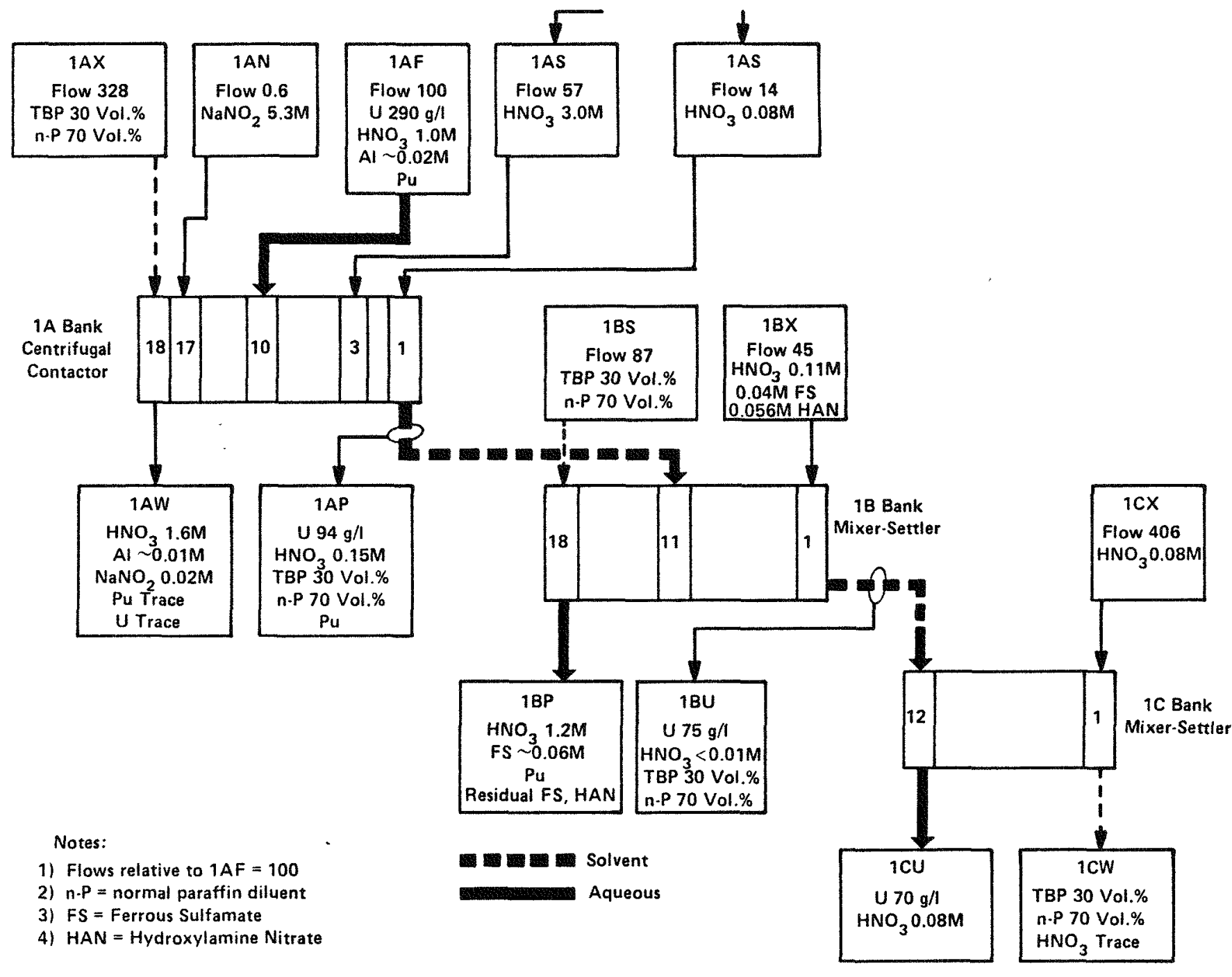

FIGURE 14. First Solvent Extraction Cycle

with Split Serub Flowsheet (1982) 
lAW, which is concentrated and then processed through an anion exchange system for plutonium and neptunium recovery; (3) the aqueous uranium product stream, $1 \mathrm{CU}$, which is concentrated and then processed through a second cycle of solvent extraction for additional decontamination from plutonium and fission products; and (4) the aqueous plutonium product stream, 1BP, which is processed through a second cycle of solvent extraction for additional fission product decontamination. At SRP, the plutonium in the 1 BP normally contains less than 50 parts uranium per million parts plutonium, and the second plutonium cycle provides no uranium decontamination. The uranium in the $1 \mathrm{CU}$ normally contains less than 10 parts plutonium per billion parts uranium, but the second uranium cycle has the routine capability of rejecting plutonium to the aqueous waste (1DW) stream by reducing plutonium in the second cycle feed (IDF) to $\mathrm{Pu}(I I I)$ with ferrous sulfamate. The IDW stream is evaporated and routed to the high activity waste processing system for plutonium recovery on the PRC.

The only fission products that are sufficiently extractable to show up as significant contaminants in product streams are ${ }^{95} \mathrm{Zr}-{ }^{95} \mathrm{Nb},{ }^{103} \mathrm{Ru}$, and ${ }^{106} \mathrm{Ru}$. 
Purex Process Equipment $1,5,9-12$

The mixing and separation of immiscible liquids to promote mass transfer involves several physical processes for the liquid phases: dispersion of droplets of one phase into the second phase, behavior of the dispersion, and coalescence of the dispersed phase. Large scale liquid-liquid extraction processes are normally performed with mixer-settlers, pulse columns, or centrifugal contractors.

The original first cycle equipment in both separations areas was mixer-settlers (Figure 15). In 1958, the small mixer-settlers in the F-Area first cycle were replaced with larger mixer-settlers with about an $8 \mathrm{X}$ capacity.

The flow pattern for a mixer-settler is shown in Figure 16. In the mixing section of a mixer-settler, the aqueous phase is drawn up by the impeller, mixed with the TBP-diluent phase and some of the recycled dispersion, and discharged into the emulsion layer. Most of the emulsion flows to the settling section, but a portion is recycled in the mixing section (Figure 16). The dispersed phases form a wide distinct band in the settling section; the coalesced phases flow to different adjacent stages through the outlet ports.

The impeller mixes the two phases and also provides the hydrostatic pressure necessary to overcome the resistance to flow caused by weirs, slots, etc., and acts like a rather inefficient pump. The impeller speed is relatively constant, regardless of the 


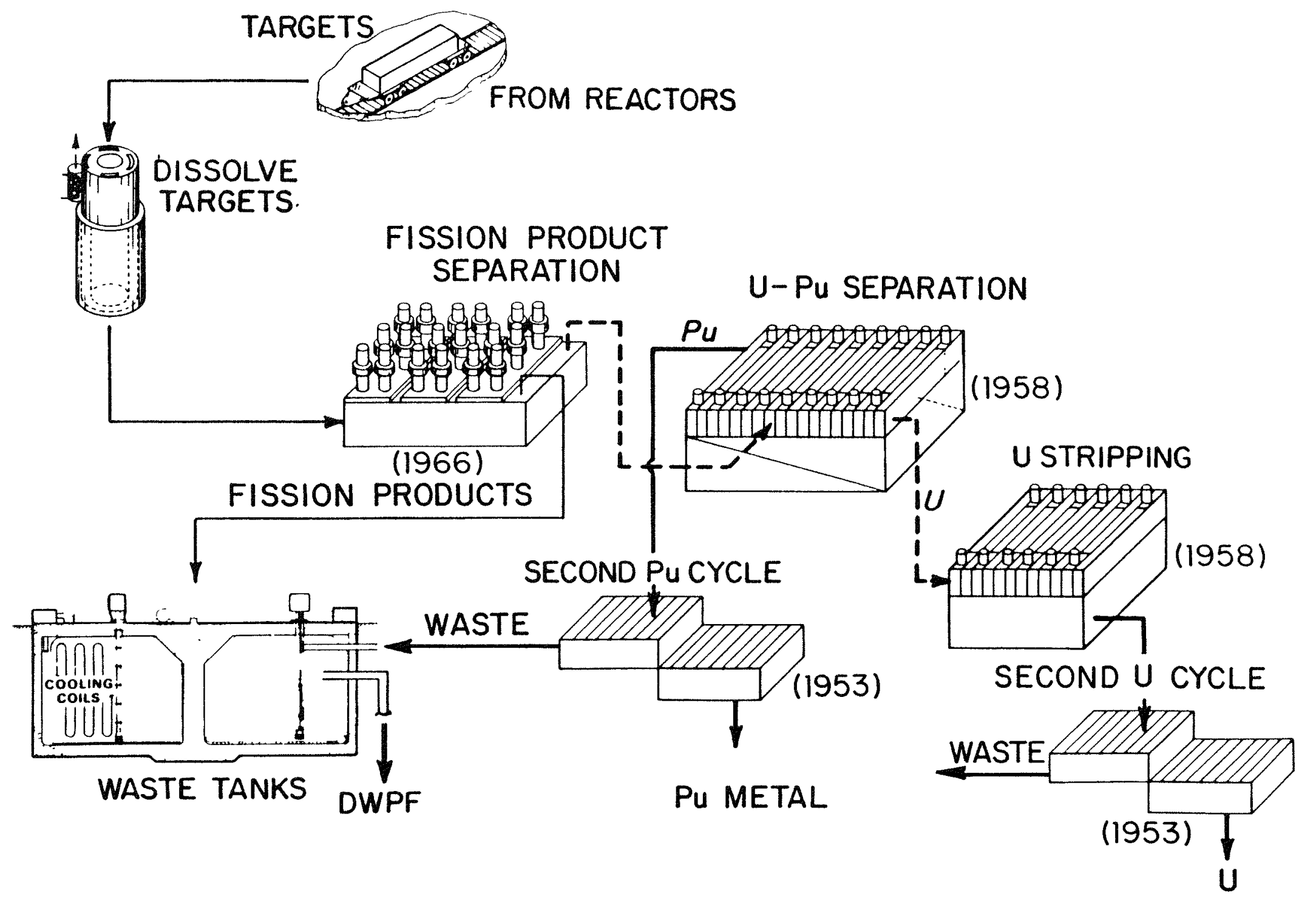

FIGURE 15. Purex Process Basic Equipment History 


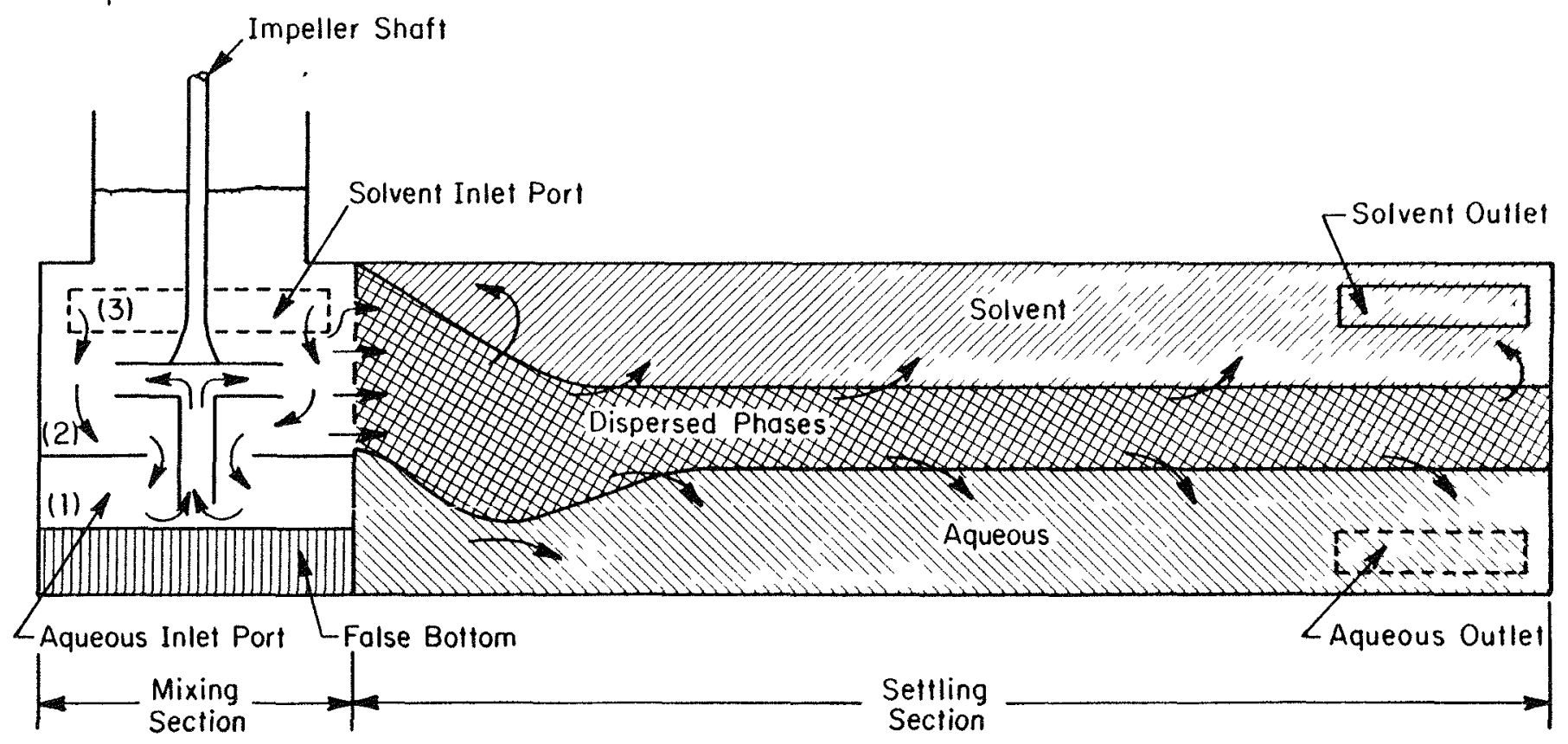

FIGURE 16. Mixer-Settlers 
flow rate. The excess mixing and pumping power recirculates the dispersed phases in the mixing chamber.

The size of dispersed droplets (typically 0.2 to $2.0 \mathrm{~mm}$ in diameter) appeared to be primarily determined by the mixing speed. The physical arrangement of the mixing chamber (Figure 16) normally favors ejecting aqueous drops into an organic medium, thus leading to an organic-continuous dispersion.

The emulsion flows into the settling section and forms a band either just above or just below the interface, depending on whether the continuous phase of the emulsion is the light or heavy phase. At relatively low flow rates, the emulsion band forms a vertical "wedge" (Figure 17); the thickest emulsion forms where the dispersion flows from the mixing section and become thinner as it flows further into the settling section. In large scale equipment, this band may be 25 to $30 \mathrm{~cm}$ thick.

Coalescence normally limits the capacity of solvent extraction equipment, except with centrifugal contactors. Mechanical phase mixing requires a time of the order of a fraction of a second, but phase separation normally requires residence times on the order of a few minutes and can be influenced by mass transfer between phases.

Observations in large scale equipment find that the major coalescent mechanism is between the droplets and the bulk phase, rather than a coalescence of droplets to form larger droplets that again coalesce and finally coalesce with the bulk phase. However, 


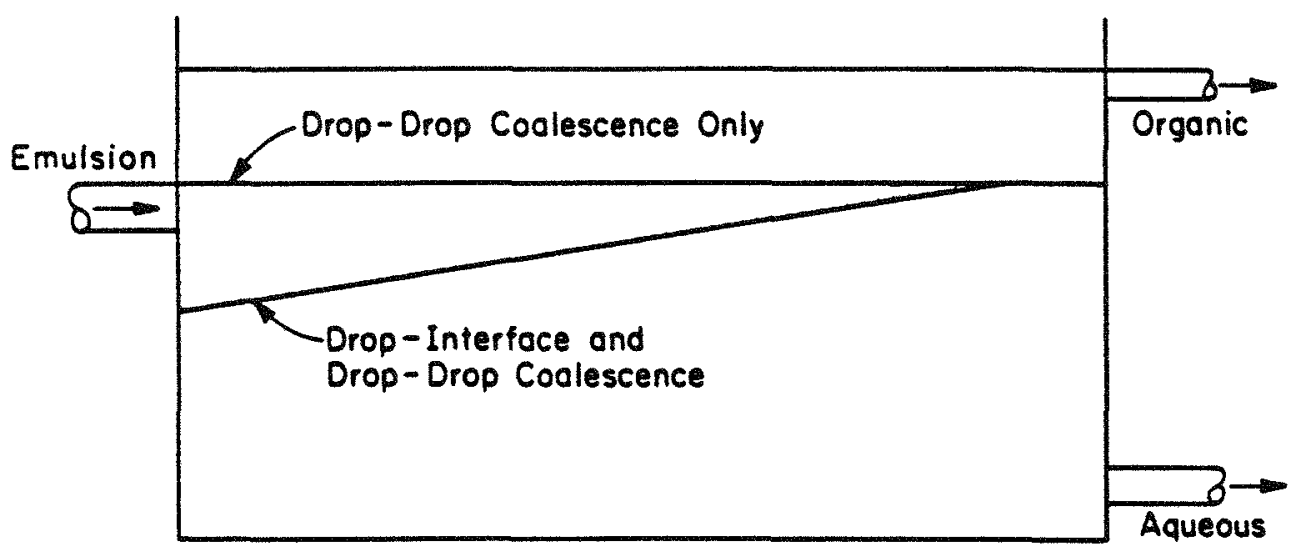

FIGURE 17. Schenatic Diagram of Coalescence "Wedge" Observed in Mixer-Settler Organic-Continuous Dispersions 
coalescence of droplets was also observed in large equipment. Both drop-drop and drop-interface coalescence must occur in a thick emulsion since the dispersed drops in the region of the emulsion-continuous phase boundary can only coalesce by a drop-drop interaction. The "streaming" of the continuous phase of the emulsion toward the bulk continuous phase acts to separate the dispersed drops and decreases the contact between them necessary for coalescence.

Studies of the size of the dispersed drop versus distance from the emulsion inlet to the settling reaction indicate that there is a region near the inlet where the drops pack into a fairly stable configuration with little coalescence. Within a few centimeters, drops begin to grow in size, most rapidly at the interface where drop-drop and drop-interface coalescence is occurring. Near the continuous phase interface, only drop-drop coalescence can occur. The increase in drop size requires two to three times as long to reach the same size as near the interface between the eumlsion and the bulk layer of the dispersed phase. The times required for drop-drop coalescence are of the order of 4 to 10 seconds for 0.9 mm drops, and longer times are required for smaller drops. "Haze" represents very small drops whose coalescence times are of the order of 20 to 30 minutes, and thus are entrained in the continuous phase. Although drop-interface coalescence is 5 to 10 times as rapid as drop-drop coalescence, residence time for a settling reaction is normally of the order of several minutes. The settling 
time required is normally the major factor in determining the capacity of a mixer-settler.

Centrifugal contactors (Figure 15) were developed at SRL during the early 1960 's for replacement of the large mixer-settlers. The long residence times in the first cycle mixer-settlers allowed the solvent to become degraded through prolonged contact with the highly radioactive solutions. These centrifugal contactors have been used in the F-Canyon lA bank of first cycle since 1966 with excellent results.

Centrifugal contactors (Figure 18) are analogous in their operation to mixer-settlers. They are stage-wise liquid-1iquid contacting devices with gravity being replaced by centrifugal force for phase separation.

Because the residence time requirement for settling in a centrifugal field is not as great as for gravity settling, several advantages relating to the resulting smaller stage volume are immediately apparent. These include reduced solvent degradation from decreased exposure time, simple accountability, ease of flushing, rapid startup, and improved nuclear safety.

Argonne National Laboratory (ANL) developed an improved design based on the original SRP concept. Figure 19 provides a cut-away view of the advanced contactor. In this design, mixing is accomplished through Taylor vortices induced by couette flow in the annulus between the rotating bowl and the stationary housing rather than with a paddle mixer as in the currently installed SRP 


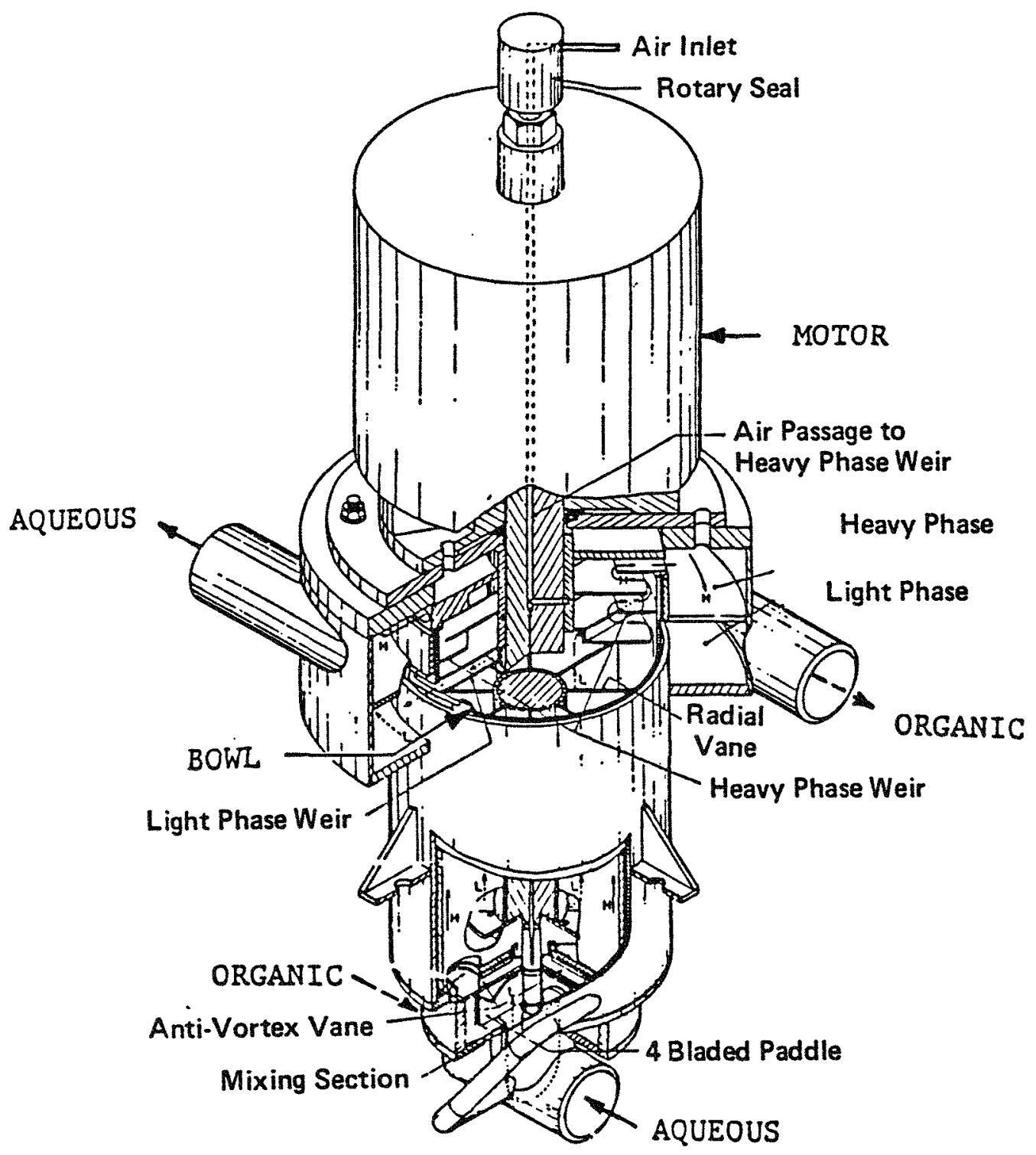

FIGURE 18. Centrifugal Contactor 


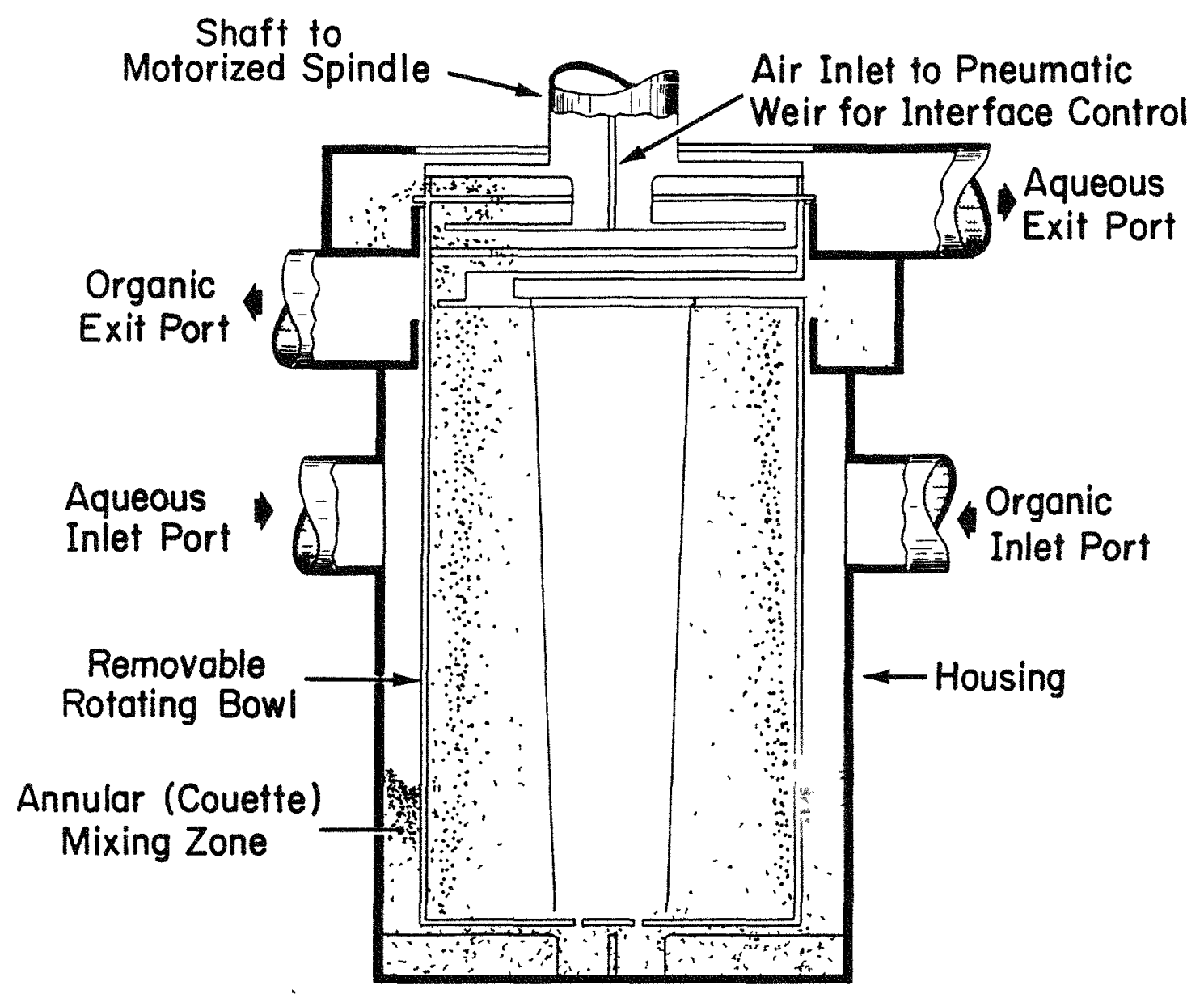

FIGURE 19. Cut-Away View of Advanced Contactor 
contactors. This concept greatly simplifies shaft design and permits the rotating bowl to be easily removed, if needed, during maintenance.

In operation, the immiscible liquids (aqueous and organic) flow into the side of the stationary housing. The two liquids then flow downward in the annular space between the stationary housing and the rotating bowl. Taylor vortices are set up in the annulus, causing droplet breakup of the dispersed phase. From the annulus, the coarse emulsion flows into the bottom of the rotating bowl. Inside the bowl, centrifugal force causes the heavier liquid to be forced to the outside of the bowl and the lighter to move to the inside. The lighter liquid flows over a weir and into a collector ring from which it then flows to the next stage in series. The heavier liquid flows under and over a series of weirs designed to maintain the interface in the rotor through air pressure in the weir space.

At the Savannah River Laboratory, centrifugal contactors have been fabricated and tested that provide combined (organic plus aqueous) flows ranging from $20 \mathrm{cc} / \mathrm{minute}$ to $230 \mathrm{liters} / \mathrm{minute}$ (Figure 20). The design utilizes comercially available components where possible to minimize the cost of fabrication. Commercially available motorized milling machine spindles are used as individual drive motors on the larger machines. A system of toothed belts and a single motor for a multistage array has been employed on the 


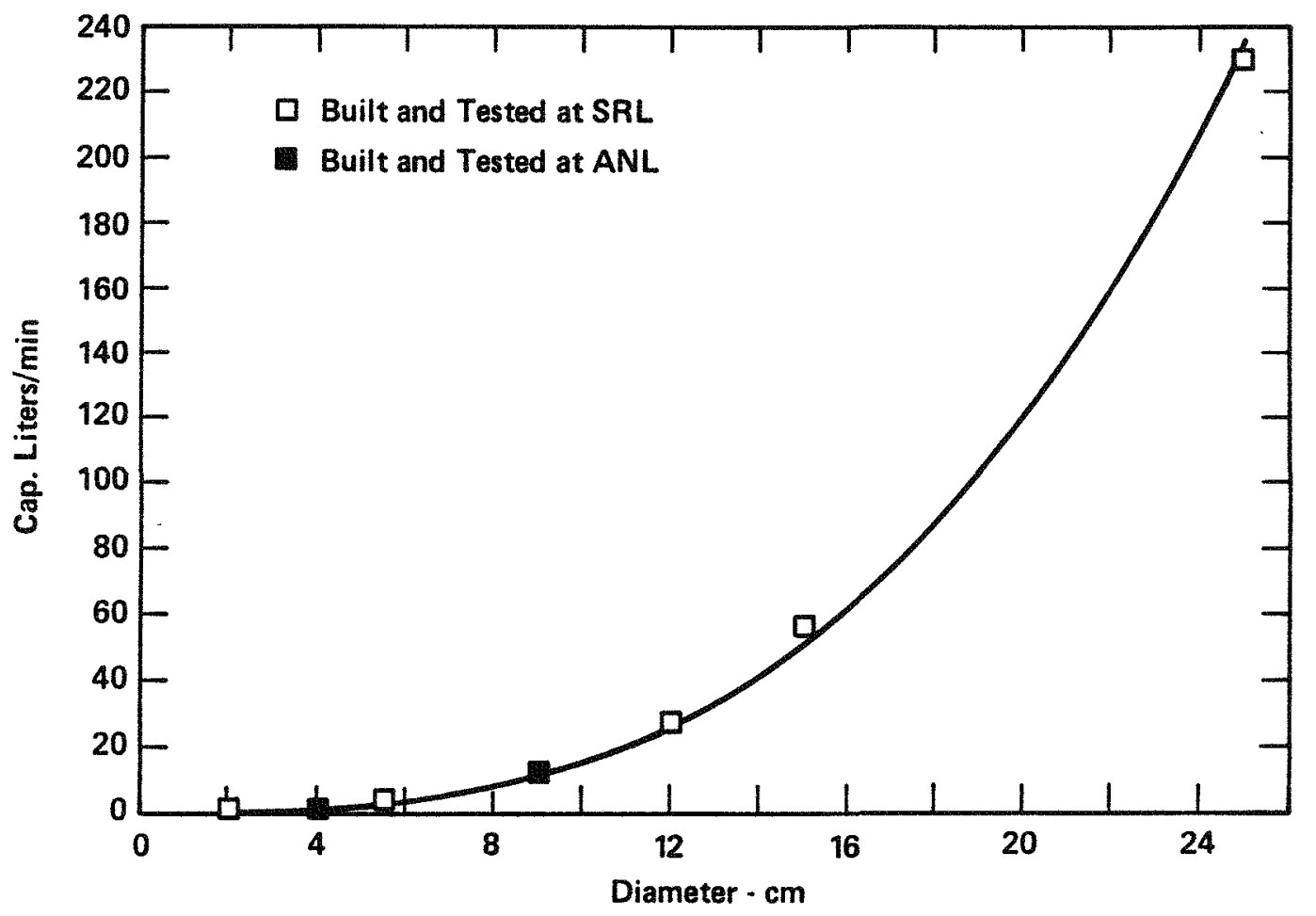

FIGURE 20. Centrifugal Contactor (Capacities) 
laboratory scale machines. Careful attention to array layout has resulted in extremely compact designs for multistage arrays.

Production of Plutonium Metal $13-16$

Finishing Process Chemistry 14

The finished plutonium metal product looks much like other metals, with the common silvery luster. But plutonium cannot exist in large pieces because a violent nuclear chain reaction would promptly occur. In fact, batch sizes in this plant must be limited to small "buttons" that a man can hold in his hand (see Figure 21). Plutonium is a very dense metal, as heavy as gold. An impressive property is that a relatively large piece of the metal is warm to the touch--because of the energy given off in alpha decay.

As a radioactive material, plutonium is not particularly hard to handle. Plutonium-239 has a half 1 ife of about 24,000 years and decays to uranium-235 by emitting an alpha particle. Alpha particles have very low penetrating power, so that shielding is not required after the hard gamma emitting fission products have been removed. But plutonium is a heavy metal poison when absorbed by the body. Safety considerations are, therefore: 


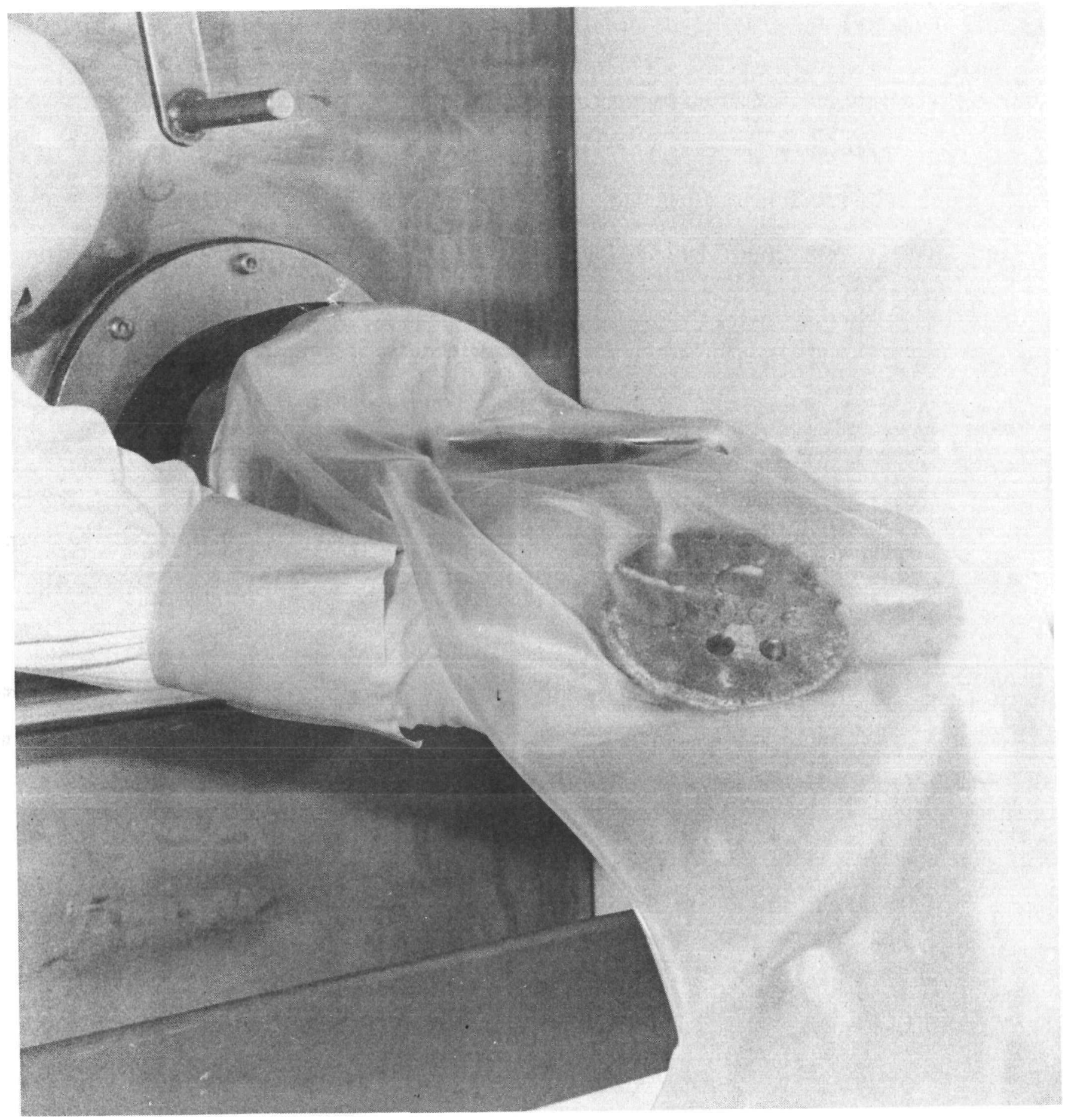

FIGURE 21. Plutonium Button 
- Preventing contamination and potential assimilations

- Limiting the amount of material to below critical mass

- Shielding the workers from neutrons induced by alpha-neutron reactions such as ${ }^{19} \mathrm{~F}$ (alpha, neutron) ${ }^{22} \mathrm{Na}$

These considerations lead to some odd contrasts in size and processing methods at Savannah River. Whereas the canyon equipment is conventional scale for the chemical processing industry, a person familiar with conventional metal production might shrug off the plutonium finishing line as "pilot plant scale." This nuclear age metal is currently produced in batch processes, using relatively simple equipment and many hand operations.

As given above, the Purex process separates the plutonium from uranium and fission products by solvent extraction. The product from this step, a dilute solution of plutonium in nitric acid, containing some residual fission products and uranium, is the feed to the plutonium finishing line. The plutonium is in the three valence state, stabilized by hydroxylamine nitrate. This solution must still go through four major process steps (Figure 22) to form the metal:

- Ion exchange for concentration and purification

- Precipitation of plutonium as the trifluoride

o Drying and conversion to $\mathrm{PuF}_{4} / \mathrm{PuO}_{2}$ mixture

- Reduction of plutonium fluoride-oxide to the metal 


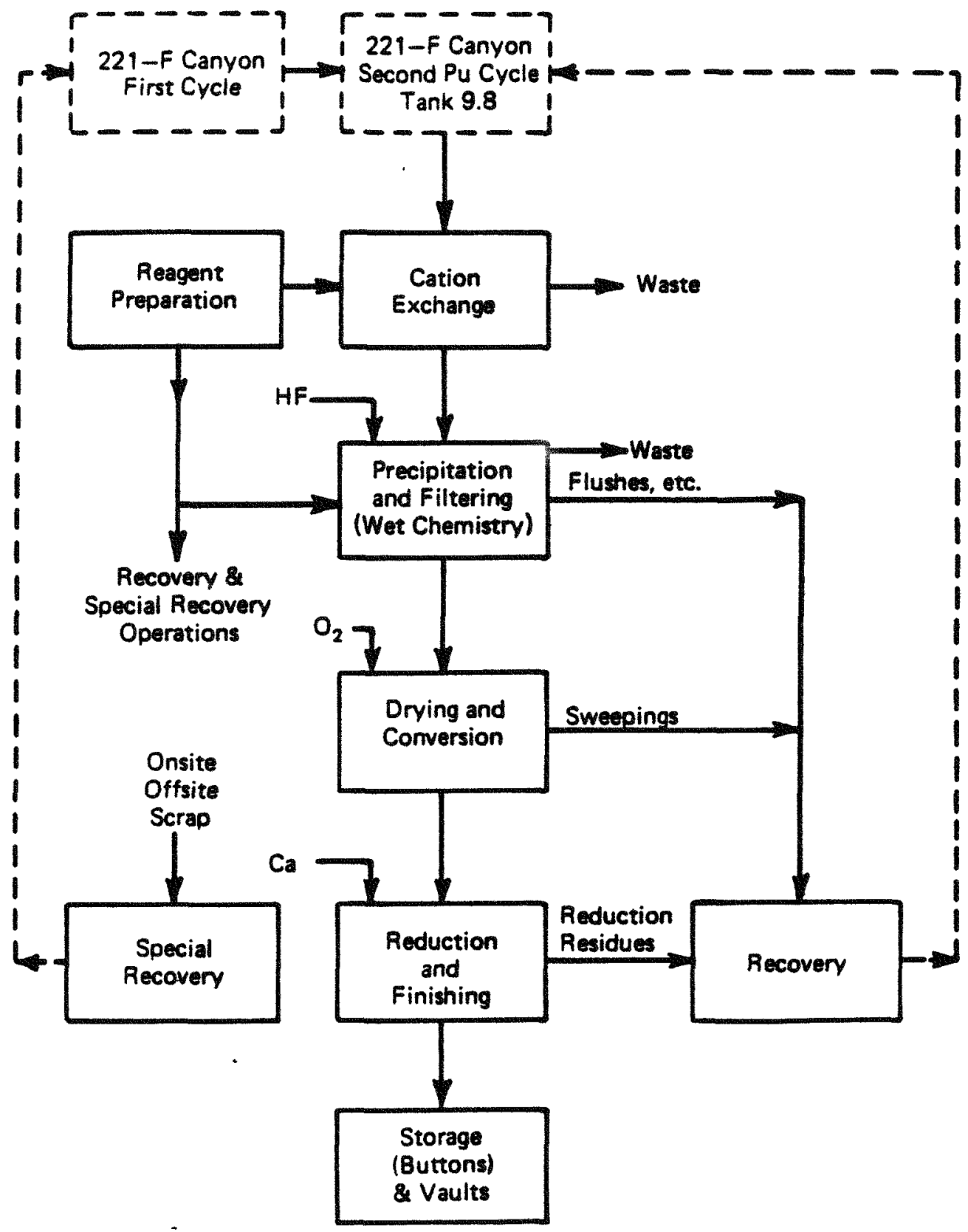

FIGURE 22. FB-Line Process flow Diagram (General) 
The chemistry of these processes is not new, but product quality and efficiency of operation depend greatly on equipment used and methods of operation.

Operating conditions and procedures that are used represent a compromise among many, often conflicting, considerations of waste loss, product purity, and recycle volumes. The typical operation ranges given represent the ranges of conditions that have been handled successfully during years of operation and show the flexibility of the process. In practice, fixed operating conditions have been maintained for months at a time.

\section{Cation Exchange Concentration 14}

A cation exchange process is the first step in the preparation of metal. Requirements for this isolation step are:

- Additional decontamination

- Low waste losses

- Ability to process dilute feed

- A suitable product for subsequent precipitation, both in concentration and chemical composition

The exchange units are small fixed bed columns containing cation exchange resin, with dimensions fixed by requirements of nuclear safety. The process was developed at the Oak Ridge National Laboratory, Oak Ridge, Tennessee. As described in the flow diagram, Table 3, plutonium is absorbed on Dowex 50W from the dilute nitric acid feed solution 
TABLE 3

Flow Diagram for Ion Exchange Process

The columns are operated on a batch basis, with counter-flow absorption and elution.

- The feed (solvent extraction plant product solution) flows down through the column until a desired load of plutonium has been absorbed.

- A wash of dilute sulfuric acid down the column removes absorbed uranium and fission products (optional).

- Eluting solution flows up through the column and the bulk of the plutonium solution is removed, leaving a heel (normal operations).

- An upflow reconditioning wash restores the low acid condition, making the column ready for the next cycle.

- Eluate may be divided into fractions depending on plutonium content (if desired). A rich portion can be taken for the product fraction, while fore and tailing fractions can be recycled.

- Nonroutine column operations include extended product elution for heel removal, refrigerated wash for degassing or reduction of $\mathrm{Pu}(\mathrm{IV})$, and fission product elution if the column accumulates too much activity.

\section{Absorption}

Feed

Plutonium, $g / L$

$\mathrm{HNO}_{3}, \mathrm{M}$

$\mathrm{NH}_{2} \mathrm{OH} \mathrm{HNO}_{3}, \mathrm{M}$

Absorption Batch, ${ }^{a} \mathrm{~g} \mathrm{Pu}$

Flow Rate, $\mathrm{mL} / \mathrm{min} / \mathrm{sq} \mathrm{cm}$

Losses (absorption and decontamination wash), $\%$

${ }^{a}$ Amount loaded in addition to the heel.

$-1000$

$10-20$
Elution and Reconditioning

Volume Changes

Elutriant

$1.6-4.0$

$0.2-0.6$

$0.025-0.05$

$10^{-4}-10^{-1}$

Pu Concentration, g/L
Reconditioning Wash

Product Fraction

$30-35$

Flow Rates, $\mathrm{mL} / \mathrm{min} / \mathrm{sq} \mathrm{cm}$ Elutriant Reconditioning Wash

$0.2-0.5$

$0.2-0.8$

2

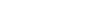

\section{.}

.


produced by the solvent extraction process and is eluted by strong acid.

At SRP, the $\mathrm{Pu}(\mathrm{III})$ system is favored over $\mathrm{Pu}(\mathrm{IV})$ for several reasons:

o No further feed adjustment is required for ion exchange, as $\mathrm{Pu}(\mathrm{III})$ is the product of the prior solvent extraction step. - Sulfate decontamination wash to remove $\mathrm{UO}_{2}{ }^{2+}$ and ${ }^{95} \mathrm{Zr}-{ }^{95} \mathrm{Nb}$ would complex $\mathrm{Pu}(\mathrm{IV})$ with resulting high losses from the column.

- Capacity of the resin (hence the column batch size) is larger with $\mathrm{Pu}(\mathrm{III})$ than with $\mathrm{Pu}(\mathrm{IV})$.

- Elution curve of $\mathrm{Pu}(\mathrm{III})$ is sharper, resulting in minimum time cycles and higher concentrations of plutonium in the eluate. One potential problem with $\mathrm{Pu}(\mathrm{III})$ is its instability with respect to oxidation to $\mathrm{Pu}(\mathrm{IV})$ in strong nitric acid. The reaction can become autocatalytic with vigorous evolution of nitrogen oxide gases. However, the oxidation rate is dependent on concentration. By experience, there is little chance of rapid oxidation if sulfamic acid stabilizer is present and if the peak concentration of plutonium in the strong acid eluting solution is less than 130 grams per liter. By avoiding concentrations above this level, many months of operation have been maintained without appreciable oxidation. The $\mathrm{Pu}(\mathrm{III})$ is stabilized by hydroxylamine in dilute ( $<2$ M) nitric acid solutions and by sulfamic acid in strong acid $\left(<3 \mathrm{M} \mathrm{HNO}_{3}\right)$. 
Gas within the resin bed interferes with fluid flow and with the solution-resin exchange. It may be formed in the oxidation of plutonium by free radicals generated by radiolysis of nitric acid solution when a loaded column remains idle, or by reactions of the free radicals with the reducing agents (hydroxylamine and sulfamic acid). This gas can be removed, and any $\mathrm{Pu}(\mathrm{IV})$ in the column reduced to $\mathrm{Pu}(\mathrm{III})$, with a refrigerated wash of dilute solution of nitric acid and hydroxylamine.

Separation of impurities from plutonium by the cation exchange resin occurs by several mechanisms:

- Anionic or nonionized impurities, or weakly absorbed cations, pass through the resin unabsorbed

- Materials that are absorbed less strongly than plutonium are displaced downward during absorption

- Materials that are held more strongly than plutonium in the elutriant solution are left on the resin

- Materials complexed preferentially by sulfate are selectively removed from the resin with the decontamination wash.

\section{Precipitation of Pletoniu Triflaoride 15,16}

Production of pure plutonium metal from cation exchange concentrate requires a further series of chemical operations. The original plutonium finishing facilities at SRP utilized the precipitation of plutonium peroxide, which, after drying, was converted to plutonium tetrafluoride for reduction to metal. 
Significant simplification of this cycle was achieved by precipitating the fluoride directly, thus eliminating the fluorination step. However, direct precipitation of the fluoride does not eliminate the corrosion problems.

Direct precipitation of the tetrafluoride is an impractical route, since the hydrated precipitate is putty-like and difficult to filter. Dehydration of the hydrate $\mathrm{PuF}_{4} \cdot 2.5 \mathrm{H}_{2} \mathrm{O}$ to an anhydrous material required for downstream processing is very difficult. Typically, vacuum dehydration results in the following net reactions, the equilibrium being displaced to the right in vacuum:

$\mathrm{PuF}_{4} \cdot 2.5 \mathrm{H}_{2} \mathrm{O} \longrightarrow \mathrm{PuF}_{4} \cdot \mathrm{H}_{2} \mathrm{O}+1.5 \mathrm{H}_{2} \mathrm{O}(\mathrm{g})$

$\mathrm{PuF}_{4} \cdot \mathrm{H}_{2} \mathrm{O} \longrightarrow \mathrm{PuF}_{4}+\mathrm{H}_{2} \mathrm{O}(\mathrm{g})$

$4 \mathrm{PuF}_{4}+2 \mathrm{H}_{2} \mathrm{O} \longrightarrow 4 \mathrm{PuF}_{3}+4 \mathrm{HF}(\mathrm{g})+\mathrm{O}_{2}(\mathrm{~g})$

Two halides, $\mathrm{CaPuF}_{6}$ and $\mathrm{PuF}_{3}$, may be prepared by precipitation and then dehydration. Both can then be reduced to the metal. Only the trifluoride precipitation process has been employed on a plant scale.

The advantages of the trifluoride route are that it offers a precipitation agent (hydrofluoric acid) that is thermodynamically stable, and filtrate losses are sufficiently low to be discarded as waste. The precipitate, $\mathrm{PuF}_{3}$, is thermodynamically stable, is not hydrated, can be dried readily, and it can be reduced directly with calcium and an iodine booster without the use of a fluorination furnace. Alternately, the anhydrous $\mathrm{PuF}_{3}$ can be 
oxidized with dry oxygen to a mixture of $\mathrm{PuF}_{4}$ and $\mathrm{PuO}_{2}$ which has sufficient heat of reduction to be reduced with calcium alone. In addition, the stabilized Pu(III) nitrate solution produced by cation exchange is a natural feed for any system that requires tripositive plutonium.

The plutonium trifluoride route to metal parallels methods using the peroxide or oxalate: precipitation from a concentrated solution to isolate a solid compound, a high temperature furnace operation to remove impurities and give a form suitable for reduction, and reaction with calcium to give plutonium metal. The trifluoride reaction path which has been used at the Savannah River $\mathrm{Plant}$ is shown in Figure 23.

Successful plant operation includes formation of a precipitate that can be easily filtered and dried, maintenance of low loss levels, and continuity of operations. In the trifluoride system, these points are related directly to control of oxidation state, to maintenance of proper crystal growth conditions, and to control of "plating" (growth of an adherent layer of precipitate on equipment surfaces). A two-stage precipitation unit has been used to satisfy the sometimes conflicting requirements of large product crystals and low losses. Plutonium feed solution and hydrofluoric acid are added simultaneously to the first stage, where conditions of solubility that favor crystal growth are maintained. The slurry overflows into a second stage, where sufficient hydrofluoric acid is added to give low final solubility. 


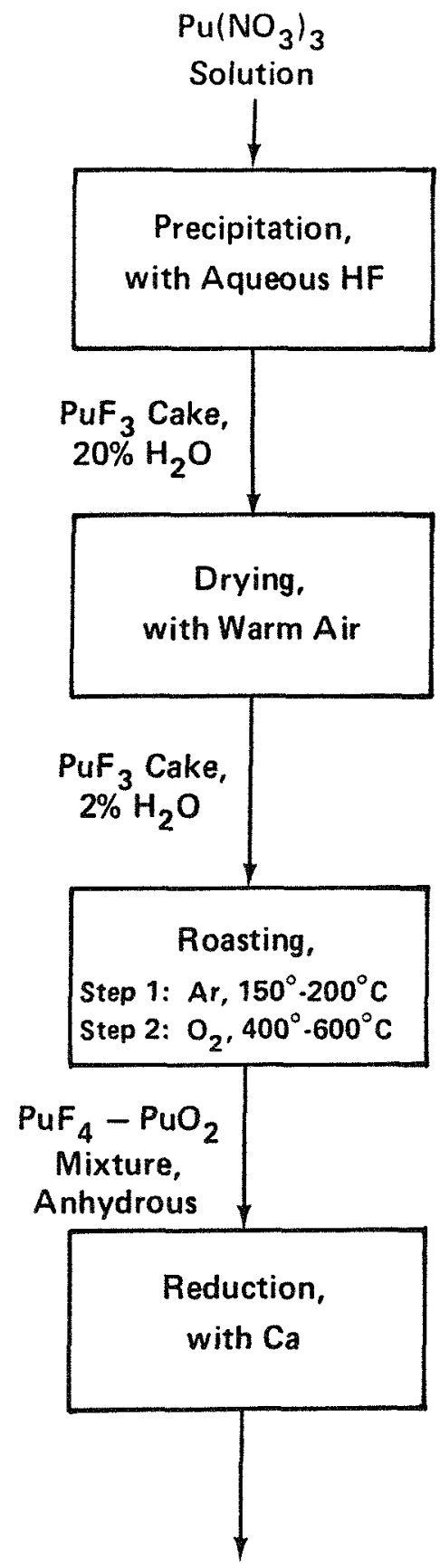

Pu Metal

FIGURE 23. Plutoniu Isolation and Conversion to Metal 
Since hydrofluoric acid is a weak acid, the solubility of $\mathrm{Pu}(\mathrm{II})$, according to the primary precipitation equation, is a function of the $\mathrm{HNO}_{3} / \mathrm{HF}$ ratio:

Precipitation reaction

$$
\mathrm{Pu}\left(\mathrm{NO}_{3}\right)_{3}+3 \mathrm{HF} \longrightarrow \mathrm{PuF}_{3}+3 \mathrm{HNO}_{3}
$$

where the final equilibrium is fixed by the constants:

Pu solubility, $\mathrm{K}_{\mathrm{sp}}=2.4 \times 10^{-16}$

$\mathrm{HF}$ ionization, $\mathrm{K}_{\mathrm{a}}=7.2 \times 10^{-4}$

Operation of the two-stage unit is very sensitive to the ratio of acids. For the first stage, a $\mathrm{HNO}_{3} / \mathrm{HF}$ ratio greater than 6 , at total nitric acid concentration of 3 to $5 \mathrm{M}$, gives adequate crystal growth conditions and consequent ease of final filtration. In the second stage, a ratio of 3 or less gives losses of 0.05 to $0.1 \%$

Crystals of almost any desired size can be made by increasing the $\mathrm{HNO}_{3} / \mathrm{HF}$ ratio in the first stage. The upper limit on this ratio is set by the ability to suspend and transfer the dense, rapidly settling crystals that can be produced. High ratios also lead to excessive crystal growth on vessel walls. This "plating" is a function of the degree of supersaturation and primarily affects first stage operation. Growth increases with vessel surface roughness, but does not appear to be influenced by the actual material of contruction. The $\mathrm{HNO}_{3} / \mathrm{HF}$ ratio used in the first stage is usually between 7 to 1 and 8 to 1 ; the exact number 
depends upon current performance as determined by settling characteristics, filtration time, plating, etc.

Special efforts must be made to prevent the trifluoride from oxidizing during precipitation from nitric acid solutions, because the hydrated tetrafluoride $\left(\mathrm{PuF}_{4} \cdot 2.5 \mathrm{H}_{2} \mathrm{O}\right)$ that is formed has a higher solubility (hence higher loss) and is an adherent, puttylike, unfilterable material under these operating conditions. The ion exchange concentration contains sulfamic acid and hydroxylamine, which act as oxidation inhibitors.

Ascorbic acid has the ability to reduce $\mathrm{Pu}(\mathrm{IV})$ to $\mathrm{Pu}(\mathrm{III})$ and is added just before precipitation. It is not added earlier because it slowly forms an organic degradation product that precipitates and carries some plutonium.

\section{Drying and Conversion 16}

The trifluoride cake, after washing and a short drain period on the vacuun filtration station, contains 20 to $25 \%$ moisture by weight. It dries readily with warm air.

Air dried plutonium trifluoride cake has the approximate composition $4 \mathrm{PuF}_{3} \cdot 3 \mathrm{H}_{2} \mathrm{O}(4.4 \mathrm{wt} \%$ water $)$. This material is hydroscopic enough to gain water (if exposed to a humid atmosphere) to approximately the composition $5 \mathrm{PuF}_{3} \cdot 6 \mathrm{H}_{2} \mathrm{O}$ ( 6.4 wt \% water). Too rapid or excessive drying in the presence of oxygen can lead to hydrolys is via the reactions:

$$
4 \mathrm{PuF}_{3} \cdot 3 \mathrm{H}_{2} \mathrm{O}=4 \mathrm{PuF}_{3}+3 \mathrm{H}_{2} \mathrm{O}(\mathrm{g})
$$


$\mathrm{PuF}_{3}+2 \mathrm{H}_{2} \mathrm{O}=\mathrm{PuO}_{2}+3 \mathrm{HF}(\mathrm{g})+1 / 2 \mathrm{H}_{2}(\mathrm{~g})$

The rate of hydrolysis is proportional to the partial pressure of water in the air drying furnace atmosphere. Suction air drying and static air drying at ambient temperatures are used to minimize the amount of hydrolysis.

Roasting in a dynamic nitrogen atmosphere for 1.5 hours (minimum) at $150-200^{\circ} \mathrm{C}$ removes additional water while minimizing hydrolysis. Further heating at $500-600^{\circ} \mathrm{C}$ in a dynamic oxygen atmosphere oxidizes the plutonium via the reaction:

$4 \mathrm{PuF}_{3}(\mathrm{~s})+\mathrm{O}_{2}(\mathrm{~g})=3 \mathrm{PuF}_{4}(\mathrm{~s})+\mathrm{PuO}_{2}(\mathrm{~s})$

The converted cake produced under the normal FB-Line process atmosphere has a nominal composition of 73 mole \% PuF $4-27$ mole $\% \mathrm{PuO}_{2}$ (theoretical composition is 75 mole \% $\mathrm{PuF}_{4}-25$ mole \% $\left.\mathrm{PuO}_{2}\right)$

The atmosphere of the line must be kept dry (the nominal dew point of input air is maintained at $-30^{\circ} \mathrm{F}$ ). The cake is removed from the furnace and transferred to the reduction furnace while exposing converted cake to the line atmosphere. Moisture in the atmosphere (dew points $>-30^{\circ} \mathrm{F}$ ) will result in the sorption of approximately 0.5 wt \% water. Moisture presents two hazards in the reduction process:

- First, the exothermic reaction between calcium metal and moisture in the plutonium powder could, under certain conditions, generate enough heat to initiate the reduction 
reaction prematurely during the handling and mixing operations.

- Second, at the high temperatures reached during reduction, vaporized moisture could overpressurize the pressure chamber and expel material from the furnace.

Also, excessive hydrolysis of the calcium metal used to reduce the plutonium will lead to low yields or total misfires in the reduction step.

\section{Reduction to Metal 16}

Reduction performance is determined by the heat of reduction and by the melting point of the slag phase.

The heat values determine the temperature reached in bomb reduction reactions and the melting points determine if the products will remain molten long enough for the metal to coalesce. The heats of reduction that are of interest to our operation are shown below with the melting points of various slag components. Tetrafluoride reduction $\mathrm{PuF}_{4}+2 \mathrm{Ca}=\mathrm{Pu}+2 \mathrm{CaF}_{2} . \quad \Delta \mathrm{H}=-156 \mathrm{kcal} / \mathrm{mole} \mathrm{Pu}$ Dioxide reduction

$\mathrm{PuO}_{2}+2 \mathrm{Ca}=\mathrm{Pu}+2 \mathrm{CaO}$ $\Delta \mathrm{H}=-60 \mathrm{kcal} / \mathrm{mole} \mathrm{Pu}$ Trifluoride reduction $\mathrm{PuF}_{3}+3 / 2 \mathrm{Ca}=\mathrm{Pu}+3 / 2 \mathrm{CaF}_{2} \quad \Delta \quad \Delta \mathrm{H}=-60 \mathrm{kcal} / \mathrm{mole} \mathrm{Pu}$ Reduction of theoretical oxygenation product $3 / 4 \mathrm{PuF}_{4}+3 / 2 \mathrm{Ca}=3 / 4 \mathrm{Pu}+3 / 2 \mathrm{CaF}_{2} \quad \Delta \mathrm{H}=-117 \mathrm{kcal}$ 


$$
\begin{aligned}
& 1 / 4 \mathrm{PuO}_{2}+1 / 2 \mathrm{Ca}=1 / 4 \mathrm{Pu}+1 / 2 \mathrm{CaO} \cdot \Delta \mathrm{H}=-15 \mathrm{kcal} \\
& \text { Total } \Delta \mathrm{H}=-132 \mathrm{kcal} / \mathrm{mole} \mathrm{Pu}
\end{aligned}
$$

Melting points of various slag components, ${ }^{\circ} \mathrm{C}$

$$
\mathrm{CaF}_{2} \quad 1418
$$

$\mathrm{CaO} 2570$

$76.5 \% \mathrm{CaF}_{2}-23.5 \% \mathrm{CaO} \quad 1360$, eutectic mixture

These heats of reaction obviously are not the only factors in a heat balance, which must include total ingredients and their heat capacities between room temperature and the temperature reached during the reaction, but they are useful for comparison.

The furnace pressure chamber, which contains the plutonium tetrafluoride/dioxide powder and calcium metal in a crucible surrounded by sand, is alternately evacuated and purged with argon to remove any air from the reduction vessel. (Argon is used for this step instead of nitrogen because the nitrogen can react with the plutonium and form plutonium nitride. Also, plutonium nitride will tend to thermally decompose and the nitrogen gas generated will tend to "boil of $f^{\prime \prime}$ at initiation of the run which causes spattering.) This is done because any uncombined oxygen will result in the formation of calcium and plutonium oxides in the reduction vessel when it is above $500^{\circ} \mathrm{C}$. The net effect of these reactions is a decrease in the reduction yield.

The ceramic crucible is used to contain the reaction mixture because contact between the stainless steel pressure vessel container and the molten plutonium would result in intermetallic 
reactions. These reactions would contaminate the product, reduce the yield, and render the metal pressure vessel unusable. The crucible material and the sand in which the crucible is seated must be compatible with the recovery processes. For this reason, magnesium oxide crucibles (low silica) and sand are used in the reduction vessel. Heating the plutonium tetrafluoride-plutonium oxide-calcium metal mixture to about $550^{\circ} \mathrm{C}$ initiates the exothermic reactions given above. The temperature of this calciothermic reaction (a thermite-type reaction) mixture rapidly rises to about $1500^{\circ} \mathrm{C}$. Concurrent with this rapid temperature rise, there is an immediate decrease in the neutron and secondary gamma radiation levels because the plutonium tetrafluoride is being converted to plutonium metal. (Principally, the neutron radiation level is due to the reaction of the plutoniun alpha particles on the fluorine atoms to produce neutrons. As the plutonium is converted from the tetrafluoride to the molten metal, the molten plutonium separates from the fluoride slag and the neutron level decreases. Additionally, an abrupt decrease in gamma radiation indicates that the reaction has occurred.)

At this high temperature $\left(1500^{\circ} \mathrm{C}\right)$, the major reaction products (PuO and the $\mathrm{CaF}_{2}-\mathrm{CaO}$ mixture) are molten. Also, the fluidity of the calcium fluoride-calcium oxide mixture allows the more dense plutonium liquid to separate from this mixture and flow to the bottom of the crucible forming a button-shaped regulus. Hence, the term plutonium "button." The calcium fluoride-calcium oxide mixture is called "slag." 
The plutonium button is physically separated from the slag and the magnesium oxide crucible, and numbered for identification. The button is then pickled in nitric acid and rinsed with water. The pickling is required because the button still has small particles of slag adhering to it and because there also is a slight passivation of the button surface due to oxidation. The nitric acid dissolves these particles and the oxidation layer, thus removing them from the surface of the button. The water rinse removes the nitric acid.

The slag remaining after the reduction step largely is composed of calcium fluoride, calcium oxide, unreacted calcium metal, unreduced plutonium fluoride and oxide, and small plutonium metal droplets. Because the molten plutonium penetrates several millimeters into the wall of the magnesium oxide crubible, both the slag and crucible are packaged and stored on an interim basis, and then processed in a recovery. The pressure chamber and magnesium oxide sand are reused for other reductions.

\section{ACKMOWLBDGERT}

The information contained in this article was developed during the course of work under Contract No. DE-AC09-76SR00001 with the U.S. Department of Energy. 


\section{References.}

1. L. W. Gray, et al, "Recent Solvent Extraction Experience at Savannah River," E. I. du Pont de Nemours \& Co., Savannah River Laboratory, Aiken, SC (May 1986). Presented at the Tenth Annual Actinide Workshop, May 12-15, 1986, Los Alamos National Laboratory, Los Alamos, New Mexico.

2. E. K. Dukes, "The Savannah River Plant Environment," US DOE Report DP-1642, E. I. du Pont de Nemours \& Co., Savannah River Laboratory, Aiken, SC (March 1984).

3. T. M. Langley and W. L. Marter, "The Savannah River Plant Site," US DOE Report DP-1323, E. I. du Pont de Nemours \& Co., Savannah River Laboratory, Aiken, SC (September 1973).

4. E. B. Sheldon, "Experience with Processing Irradiated Fuel at the Savannah River Plant (1954-1976)," US DOE Report DP-1467, E. I. du Pont de Nemours \& Co., Savannah River Laboratory, Aiken, SC (September 1977).

5. J. M. McRibben, "Chemistry of the Purex Process," US DOE Report DPSPU-83-272-1, E. I. du Pont de Nemours \& Co., Savannah River Plant, Aiken, SC (March 1983). Presented at 135 th National Meeting of the American Chemical Society, March 20-25, 1983, Seattle, WA.

6. J. F. Flagg, "General Features of Nuclear Fuel Reprocessing," Chapter 1 in Chemical Processing of Reactor Fuels, Nuclear Science and Technology, Volume 1, Ed. J. F. Flagg, Academic Press, New York (1961).

7. E. L. Christensen, L. W. Gray, J. D. Navratil, and W. W. Schulz, "Present Status and Future Direction of Plutonium Process Chemistry," Chapter 23 in Plutonium Chemistry, Eds. W. T. Carnall and G. R. Choppin, ACS Symposium Series 216, American Chemical Society, Washington, DC (1983).

8. J. M. McRibben, J. B. Starks, and J. K. Brown, "The Savannah River Purex Plant - 25 Years of Successful Remote Operations," Proceedings of 27 th Conference on Remote Systems Technology, American Nuclear Society, La Grange Park, IL (1979).

9. J. B. Starks, "The Purex Process," US DOE Report DPSPU-77-11-1, E. I. du Pont de Nemours \& Co., Savannah River Laboratory, Aiken, SC (January 1977). 
10. L. L. Burger, "Physical Properties," Chapter 3 in Science and Technology of Tributyl Phosphate, Volume 1, Eds. W. W. Schulz and J. D. Navratil, CRC Press, Inc., Boca Raton, FL (1984).

11. D. A. Orth, R. M. Wallace, and D. G. Karraker, "Solvent Extraction Reactions and Mechanisms," Chapter 6 in Science and Technology of Tributyl Phosphate, Volume 1, Eds. W. W. Schulz and J. D. Navratil, CRC Press, Inc., Boca Raton, FL (1984).

12. M. E. Hodges, "Hydraulic Performance of a Multistage Array of Advanced Centrifugal Contactors," Transactions of American Nuclear Society Topical Meeting "Fuel Reprocessing and Waste Management," Jackson Hole, WY (August 1984).

13. L. W. Gray and J. H. Radke, "Plutonium Scrap Recovery at the Savannah River Plant," Chapter 1 in Actinide Recovery from Waste and Low Grade Sources," Eds. J. D. Navratil and W. W. Schulz, Harwood Academic Publishers, New York (1982).

14. E. W. Mainland, D. A. Orth, and J. H. Radke, "Product in of Plutonium Metal," Ind. and Eng. Chem., 53, 685 (1961).

15. G. A. Burney and F. W. Tober, "Precipitation of Plutonium Trifluoride," I\&EC Process Design and Development, 4, 28 (1965).

16. D. A. Orth, "Plutonium Metal from Trifluoride," I\&EC Process Design and Development, 2, 121 (1963). 